\title{
Involving men in maternity care in India
}

\author{
Leila Caleb-Varkey
}

Anurag Mishra

Population Council

Anjana Das

Emma Ottolenghi

Dale Huntington

See next page for additional authors

Follow this and additional works at: https://knowledgecommons.popcouncil.org/departments_sbsr-rh

Part of the Demography, Population, and Ecology Commons, International Public Health Commons, Maternal and Child Health Commons, and the Public Health Education and Promotion Commons How does access to this work benefit you? Let us know!

\section{Recommended Citation}

Caleb-Varkey, Leila, Anurag Mishra, Anjana Das, Emma Ottolenghi, Dale Huntington, Susan E. Adamchak, M.E. Khan, and Rick Homan. 2004. "Involving men in maternity care in India," FRONTIERS Final Report. Washington, DC: Population Council. 


\section{Authors}

Leila Caleb-Varkey, Anurag Mishra, Anjana Das, Emma Ottolenghi, Dale Huntington, Susan E. Adamchak, M.E. Khan, and Rick Homan 


\title{
Involving Men in Maternity Care in India
}

\author{
Leila Caleb Varkey, Anurag Mishra, \\ Anjana Das, Emma Ottolenghi, Dale Huntington, \\ Susan Adamchak, M.E. Khan, Frederick Homan \\ Frontiers in Reproductive Health Program \\ Population Council \\ New Delhi, India
}

April 2004

This study was funded by the United States Agency for International Development (USAID) under the terms of Cooperative Agreement Number HRN-A-00-98-00012-00 and Population Council project number 5800.13031.454. The opinions expressed herein are those of the authors and do not necessarily reflect the views of USAID. 


\section{ACKNOWLEDGEMENTS}

The Men in Maternity Study was a collaborative effort of the Employees' State Insurance Corporation (ESIC), India and the Population Council. In this report we would like to acknowledge the implementation effort of the group of 12 doctors and 12 auxiliary nurse midwives and their supervisors at the six intervention and control sites as well as the participation of couples and their newborns in this operations research study. Their enthusiastic involvement led to the success of the Men in Maternity experiment. We would like to especially mention Dr. Rakesh Chander, then ESIC's Director (Medical) Delhi, for his personal attention to the program and the management oversight provided by the ESIC Additional Directors, Dr. Malik, Dr. Kukreja, and Dr. Kathuria. We would also like to thank Nirmala Selvam for her excellent work as a consultant for the MiM training of providers, and the survey research team at TNS MODE, especially Dr. Sridhar, Dr. Sushanta Banerjee and Ms. Urmil Dosajh and their team of interviewers and supervisors for the surveys as well as the TNS MODE data entry team and consultants who helped to code and re-combine many different data files.

We are grateful to our colleagues at the Population Council, FHI and USAID, who first conceived of the idea that male involvement in maternity study was possible and encouraged and supported the global MiM study, and are currently supporting the scaling up efforts in India. 


\section{EXECUTIVE SUMMARY}

The Men in Maternity (MiM) study investigated the feasibility, acceptability and cost of a new, more comprehensive, model of maternity care that encouraged husbands' participation in their wives' antenatal and postpartum care. The study specifically assessed the impact of the intervention on family planning in the postpartum period and STI preventive practices among men and women. The study was conducted in collaboration with the Employees' State Insurance Corporation (ESIC), Delhi Directorate at their primary health facilities called dispensaries.

The MiM study used a non-equivalent control group study design to examine the effects of the intervention. Six of the 34 ESIC dispensaries in Delhi with the highest antenatal clinic attendance that also had laboratory facilities were purposively selected as study sites. Three were assigned the intervention and three acted as controls. The intervention and control dispensaries were assigned based on geographic proximity between each control and intervention dispensary. The interventions included:

- an individual or group counseling session in the antenatal clinic, separately for men and women

- couple counseling sessions during antenatal and postnatal clinics

- screening of all pregnant women for syphilis using the RPR test; and

- syndromic management of men reporting urethral discharge and men and women reporting genital ulcers as part of the individual counseling.

In the two-year intervention period a total of 2,836 women and 1,897 of their husbands were registered for couple counseling in the three intervention clinics.

The pre-intervention survey was conducted at the intervention and control sites among all women who were between 10 and 26 weeks pregnant, and who consented to participate and to allow interviews with their husbands at the enrollment time (intervention group only) and at 6 months postpartum at home until the desired sample size was achieved. A total of 581 pregnant women at intervention and 486 at control sites were interviewed (pre) when they came for a first antenatal visit. Four hundred and eighty eight husbands of clients at intervention sites were interviewed at the pre survey. At the post survey, 327 women and their husbands from the intervention group and 302 women and their husbands from the control group were interviewed. The large loss to follow-up was due to couples not being at home and to difficulties locating addresses given at the time of the pre survey. Actual refusals to take part in the study were negligible.

After testing the comparability between the intervention and control groups on sociodemographic characteristics using data from the pre survey, results were compared with post survey data. An analysis of variance was carried out to test for cluster effects between the six dispensaries. The cluster effect was calculated and z-statistics were adjusted when testing for significant differences between the control and the intervention group. Except for questions on individual's knowledge or attitudes, where changes from pre to post were analyzed, the analysis compared intervention and control responses in the post. The report draws the following conclusions: 


\section{Comparison of General Characteristics: Intervention and Control}

- With minor differences, control and intervention women were quite similar in their socio-demographic characteristics and in reports of their husband's characteristics.

\section{Family Planning Knowledge and Use}

- Knowledge of condoms for dual protection increased in both intervention women and men compared to controls $\left(\mathrm{z}_{\mathrm{w}}=2.13, \mathrm{p}<0.05\right),\left(\mathrm{z}_{\mathrm{m}}=2.62, \mathrm{p}<0.05\right)$. The net increase in women's knowledge of family planning from pre to post survey was, however, not significantly different between the two groups $\left(\mathrm{z}_{\mathrm{w}}=0.83\right)$

- Knowledge that breastfeeding can prevent pregnancy increased significantly in intervention women and men compared to controls $\left(\mathrm{z}_{\mathrm{w}}=4.89, \mathrm{p}<0.05\right)\left(\mathrm{z}_{\mathrm{m}}=1.95, \mathrm{p}<0.05\right)$, however, there was no change in men and women's knowledge of the three conditions of LAM.

- Family planning use between six to nine months postpartum was significantly higher among women and men in the intervention group compared to the control group $\left(\mathrm{z}_{\mathrm{w}}=2.70, \mathrm{p}<0.05\right)\left(\mathrm{z}_{\mathrm{m}}=3.39, \mathrm{p}<0.05\right)$. The largest increase was reported in condom use.

- Among non-users, women from the intervention group reported significantly higher intention to use a family planning method, compared to control group women $\left(\mathrm{z}_{\mathrm{w}}=3.12\right.$, $\mathrm{p}<0.05)$. There was no significant difference in family planning intention between men's groups.

\section{STI Preventive Behaviors}

- With the above exception of the dual protection offered by condoms, STI awareness and knowledge did not increase significantly after the intervention. In general STI knowledge was lower in women than men, and there was greater knowledge about HIV/AIDS than of other STIs.

- There were very few self-reported STI risk behaviors and symptoms by either men or women. The small numbers did not allow for further statistical analysis.

- Very few women (13 percent) and men (4 percent) reported using condoms for dual protection. No difference was observed between intervention and control groups.

\section{Pregnancy Danger Signs}

- Knowledge of danger signs was significantly higher among the intervention group women ( 24 percent) compared to 13 percent of the control group women $\left(\mathrm{z}_{\mathrm{w}}=2.99\right.$ $\mathrm{p}<0.05)$. There was no appreciable difference in knowledge of danger signs among men and only 8 percent of men reported knowing any symptoms.

\section{Syphilis Testing}

- There was a significant increase in screening of pregnant women for syphilis with the establishment of a universal syphilis screening program using the RPR test. Service statistics reported 16 percent of the control clinics antenatal women were screened and more than 90 percent of women in the intervention clinics $\left(\mathrm{z}_{\mathrm{w}}=23.10 \mathrm{p}<0.05\right)$. 


\section{Gender Roles and Decision-making}

- A majority of both men and women from both the groups felt that husbands' involvement in maternity care is important. This did not change significantly for either group or from PRE to POST survey.

- Husbands' actual involvement was significantly higher in the intervention group compared to the control group during antenatal consultation $\left(\mathrm{z}_{\mathrm{w}}=4.21 \mathrm{p}<0.05\right)$, family planning consultation $\left(\mathrm{z}_{\mathrm{w}}=4.17 \mathrm{p}<0.05\right)$, postpartum visit $\left(\mathrm{z}_{\mathrm{w}}=2.10 \mathrm{p}<0.05\right)$, and presence during labor and delivery $\left(\mathrm{z}_{\mathrm{w}}=2.29 \mathrm{p}<0.05\right)$. Presence during physical examination remained low in both groups.

- Intervention group women and men reported significantly higher inter-spousal communication in the postpartum period on baby's health $\left(\mathrm{z}_{\mathrm{w}}=2.29 \mathrm{p}<0.05\right)$, breastfeeding $\left(\mathrm{z}_{\mathrm{w}}=3.91, \mathrm{p}<0.05\right)$, and family planning issues $\left(\mathrm{z}_{\mathrm{w}}=4.94, \mathrm{p}<0.05\right)$. Communication on STIs was low and did not significantly increase.

- More women from the intervention group compared to the control group reported making joint decisions on family health and family planning issues $(\mathrm{p}<0.05$ in most cases).

\section{Infant Health Indicators}

- There was no significant difference in the proportion of infants immunized in both groups; they were uniformly high.

- The percentage of women exclusively breastfeeding until 6 months was significantly less in the intervention group than the control group $\left(\mathrm{z}_{\mathrm{w}}=-2.60 \mathrm{p}<0.05\right)$. However, significantly more women in the intervention group reported that their baby was breastfed within the first hour than in the control group $\left(\mathrm{z}_{\mathrm{w}}=3.28 \mathrm{p}<0.05\right)$ and more intervention women were supplementing their babies' diet at the six to nine month follow-up than control group women $\left(\mathrm{z}_{\mathrm{w}}=5.2 \mathrm{p}<0.05\right)$.

\section{Client-Provider Interaction and Satisfaction}

- Significantly more men and women from the intervention group reported client-provider discussions during maternity care than the control group $\left(\mathrm{z}_{\mathrm{m}}=9.7, \mathrm{p}<0.05\right.$ and $\mathrm{z}_{\mathrm{w}}=8.7$, $\mathrm{p}<0.05)$. More clients from the intervention group as against the control group reported discussions on family planning during the antenatal period $\left(\mathrm{z}_{\mathrm{m}}=10.6, \mathrm{p}<0.05\right.$ and $\mathrm{z}_{\mathrm{w}}=9.8$, $\mathrm{p}<0.05)$.

- All the intervention group clients who received couple counseling reported that they were satisfied with the maternity care services. None reported that counseling caused any problem within the family.

- Qualitative data (FGDs and in-depth interviews) revealed that providers were more satisfied with the modified package of $\mathrm{MCH}$ services and would like to continue it.

\section{The Cost of Intervention}

- The marginal cost of implementing the intervention per dispensary per year was only about Rs.50,000 (or approx US\$ 1,100) which ESIC managers felt was feasible and affordable. Based on the outcomes and cost of the intervention, ESIC is scaling up the intervention to other dispensaries. 


\section{Conclusions}

- Men accompanied their wives to the clinics and participated actively in the intervention.

- There were significant changes in family planning knowledge and behaviors of both men and women.

- There was little acknowledgement of STI risk although knowledge and use of dual protection did increase. Syphilis testing of pregnant women was greatly improved. While 16 percent of control clinic clients were tested, 92 percent of intervention clinic clients had an RPR early in pregnancy.

- Clients who participated in the intervention reported more discussions with providers and more satisfaction with family planning methods.

- The new services were feasible and sustainable for ESIC in terms of provider time and increase in materials costs. 


\section{ABBREVIATIONS}

\begin{tabular}{|c|c|}
\hline AIDS & Acquired Immunodeficiency Syndrome \\
\hline $\mathrm{AN}$ & Antenatal \\
\hline $\mathrm{ANC}$ & Antenatal Care \\
\hline ANM & Auxiliary Nurse Midwife \\
\hline $\mathrm{BCC}$ & Behavior Change Communication \\
\hline ESIC & Employees' State Insurance Corporation \\
\hline FGD & Focus Group Discussion \\
\hline FP & Family Planning \\
\hline GU & Genital Ulcer \\
\hline HIV & Human Immunodeficiency Virus \\
\hline IEC & Information, Education and Communication \\
\hline IIPS & International Institute for Population Sciences \\
\hline LAM & Lactational Amenorrhoea Method \\
\hline $\mathrm{MCH}$ & Maternal Child Health \\
\hline MiM & Men in Maternity \\
\hline MIS & Management and Information System \\
\hline $\mathrm{NACO}$ & National AIDS Control Organisation \\
\hline NFHS & National Family Health Survey \\
\hline $\mathrm{NGO}$ & Non-Government Organization \\
\hline N.S. & Not Significant \\
\hline OR & Operations Research \\
\hline $\mathrm{PNC}$ & Postnatal Care \\
\hline POST & Postpartum follow-up survey at home \\
\hline PP & Postpartum \\
\hline PRE & Pre-intervention survey at ANC clinic \\
\hline $\mathrm{RCH}$ & Reproductive and Child Health \\
\hline $\mathrm{RH}$ & Reproductive Health \\
\hline RPR & Rapid Plasma Reagin \\
\hline STI & Sexually Transmitted Infection \\
\hline TBA & Trained Birth Attendant \\
\hline UD & Urethral Discharge \\
\hline WHO & World Health Organization \\
\hline
\end{tabular}




\section{TABLE OF CONTENTS}

Introduction $\quad 1$

$\begin{array}{ll}\text { Problem statement } & 1\end{array}$

Research questions $\quad 2$

Methodology $\quad 3$

Study design $\quad 3$

Survey eligibility criteria $\quad 5$

Sample size estimation $\quad 5$

$\begin{array}{ll}\text { Study site } & 6\end{array}$

MiM intervention $\quad 7$

Implementation of intervention $\quad 8$

$\begin{array}{lr}\text { Antenatal couple counseling } & 10\end{array}$

Monitoring the implementation of the MiM intervention 10

Behavior Change Communication and other materials supplied by MiM 11

Means to encourage husbands participation $\quad 12$

Ethical issues and informed consent $\quad 12$

$\begin{array}{ll}\text { Data collection procedures } & 13\end{array}$

$\begin{array}{ll}\text { Sampling procedures } & 13\end{array}$

$\begin{array}{ll}\text { Sampling results } & 14\end{array}$

Data analysis procedures $\quad 15$

Comparison of control and intervention group women 17

$\begin{array}{ll}\text { Comparison of control and intervention group men at pre } & 17\end{array}$

Comparison of characteristics of those lost to follow-up and those interviewed 18 at post survey

General characteristics $\quad 19$

$\begin{array}{ll}\text { Standard of living } & 19\end{array}$

$\begin{array}{ll}\text { Testing statistical significance } & 21\end{array}$

Results $\quad 22$

Participation in the intervention $\quad 22$

$\begin{array}{ll}\text { Obstetric history and birth outcomes } & 24\end{array}$

Results of the hypotheses tested 25

$\begin{array}{ll}\text { Hypothesis }-1 & 25\end{array}$

Hypothesis $-2 \quad 30$

Hypothesis $-3 \quad 32$

Hypothesis $-4 \quad 33$

$\begin{array}{ll}\text { Hypothesis }-5 & 35\end{array}$

Hypothesis $-6 \quad 38$

Hypothesis $-7 \quad 42$

$\begin{array}{ll}\text { Hypothesis }-8 & 45\end{array}$

$\begin{array}{ll}\text { Discussion } & 49\end{array}$ 
Utilization of results

$\begin{array}{lr}\text { Conclusions and recommendations } & 55\end{array}$

$\begin{array}{lr}\text { Bibliography } & 59\end{array}$

Appendices

Appendix - 1 Annual service statistics related to MiM 2000-2002

Appendix - 2 Model - I: Calculation of ICC and design effect for outcome indicators

Model - II: Calculation of ICC and design effect for outcome variables 


\section{LIST OF TABLES AND FIGURES}

Table 1 Number of living children - women's responses from PRE survey

Table 2A Comparisons of study group characteristics to test validity of sampling design

Table 2B Comparison of study group characteristics on key outcome indicators at PRE survey by follow-up status in POST survey

Table 3 Level of participation in intervention - POST survey

Table 4 Discussion on family planning with providers at antenatal and postnatal visits - POST surveys

Table 5 Outcome of index pregnancy - POST survey

Table 6 Proportion of women who are or may be pregnant at POST survey by the survival status of index pregnancy

Table 7 Family planning knowledge - control and intervention women in PRE and POST surveys

Table 8A Current use of family planning, pattern of use and intention to use POST survey

Table 8B Current family planning use by parity - POST survey

Table 9 Satisfaction with current family planning method - POST survey

Table 10 STIs and HIV/AIDS knowledge - POST survey

Table 11 Knowledge of dual protection from condoms - POST survey

Table 12 Syphilis testing and RPR results: Year 2001 and 2002

Table 13 Spousal communication on reproductive health issues - POST survey

Table 14 Proportion of reporting joint decision-making

Table 15 Husband's involvement in maternity care as reported by women and and men - POST survey

Table 16 Immunization of the index child - POST survey

Table 17 Breastfeeding practices among mothers - POST survey

Table 18 Actual experiences of danger signs and care seeking practices - POST survey

Table 19 Net increase in provider time for program implementation for three clinics

Table 20 Total resources used for program implementation for three clinics

Figure 1: Service statistics from intervention dispensaries

Figure 2: MiM sampling results 


\section{INTRODUCTION}

Men in Maternity (MiM) was an operations research study conducted by the Frontiers in Reproductive Health Program of the Population Council to investigate the impact of a new model of integrated maternity care on selected outcomes related to the reproductive health of men, women and the pregnancy. With an intermediate objective of increased male involvement, the specific objectives of the intervention were to increase postpartum family planning use and prevention of sexually transmitted infection (STI) through an increase in primary and secondary preventive practices in men and women. Two comparable studies were implemented in Delhi, India and KwaZulu Natal Province, South Africa. In India the study was conducted in collaboration with the Employees' State Insurance Corporation (ESIC), Delhi Directorate.

\section{PROBLEM STATEMENT}

In India, women depend heavily on men for access to healthcare. Studies reveal that men are the key decision makers for women's choice of health care services even though they have limited knowledge (Murthy, et al., 2002). Research also indicates that differences in socio-cultural norms of acceptable sexual behavior for men and women may put women at greater risk of STIs because of their partners' sexual behaviors, especially during pregnancy when both the woman and fetus are exposed to the risk, and when there may be greater probability of male extra-marital sexual relations due to norms of abstinence during pregnancy (Saraswati and Leonard, 2000).

Information from the National Family Health Survey, Delhi (IIPS and ORC Macro, 2002) shows that Delhi's population is generally well informed about contraception, although actual use is below intended use especially among those who are

illiterate. Seventy-four percent of all currently married women age 13-49 years use a family planning method, with condom use reported at 32 percent, and female sterilization reported by 26 percent of women. However, among the illiterate women, current use is reported by 58 percent and condom use only 6 percent. Age and education of the women influence discussions on family planning, with older women less likely to discuss these 
issues. Intention to use a family planning method among women who were not currently using a method was nearly 64 percent.

In India the rates of transmission and reporting of sexually transmitted infections have increased in the past decade. India has one of the largest numbers of people living with HIV in the world. The total estimated number of HIV positive people in India is approximately 3.97 million (NACO, 2001). The key risk factors are large migratory populations and low literacy that lead to low awareness of STIs, their treatment and strategies for prevention. Intravenous drug use, poor screening of blood and iatrogenic transmission also put individuals at increased risks. The burden of illness falls heaviest on women and youth, both of whom are biologically and socially vulnerable.

Syphilis detection and management in pregnant women is included in most antenatal service protocols. WHO maintains that this strategy is extremely cost-effective, even in very low prevalence (0.1 percent) situations. Syndromic management of men with urethral discharge (UD) or genital ulcers (GU) and partner treatment stands a better chance of success than the syndromic management of female vaginal discharge because infected men are more likely to be symptomatic than women and, conversely, men who present with symptoms are more likely to be infected than symptomatic women.

\section{RESEARCH QUESTIONS}

The MiM study was designed to answer the following questions:

1. Will men be willing, when invited, to accompany their partners to a couple oriented program during their antenatal and postnatal care?

2. If they come, what will be the impact of their participation on family planning knowledge and use, on STI knowledge and prevention, and on selected maternal and child health indicators.

The study design and eight research hypotheses were framed to address the second question: 
1. Exposure to the intervention will have a positive effect on men and women's knowledge of family planning and contraceptive practices at six months postpartum.

2. Exposure to the intervention will have a positive effect on men and women's STI preventive behaviors at six months postpartum.

3. Exposure to the intervention will increase knowledge of clients and providers about the dual protection provided by condoms.

4. Exposure to the intervention will have a positive effect on female syphilis testing and appropriate management, and treatment of male urethritis and genital ulcer disease.

5. Exposure to the intervention will have a positive effect on inter-spousal communication and support on reproductive health matters.

6. Exposure to the intervention will have a positive effect on selected indicators of infant health (e.g., immunizations, breastfeeding practices).

7. Exposure to the intervention will have a positive effect on the clients' and providers' satisfaction with antenatal and postpartum care services provided at the dispensaries.

8. The experimental intervention will produce the expected results in a cost-effective manner both in terms of its marginal cost increases as well as any additional opportunity costs that are incurred for the new services.

\section{METHODOLOGY}

\section{Study Design}

Six dispensaries were purposively selected for the MiM study by senior ESIC and FRONTIERS staff primarily based upon two criteria: high ANC attendance and an on-site laboratory. The six dispensaries selected were linked to three ESIC hospitals where a majority of women present for the delivery. Since these dispensaries happened to be in distinct geographical areas, one clinic was selected as a control and one as intervention from each of the three areas of Delhi - Northwest, West and South Delhi. All the dispensaries had laboratory facilities and sufficient doctors and nurses to conduct the study with no need for new staff. If the intervention proved successful, the existing structure of the ESIC service delivery system would allow for scale up within Delhi, and from there, to other states in India. 
The study utilized a non-equivalent control group design, in which three dispensaries provided the intervention while three others functioned as control sites. The study compared experiences of a cohort of ANC women (selected at the time of an early ANC visit) until six months postpartum. All husbands of the ANC women who were interviewed at the pre were contacted and requested for interview at home in the post interviews. Only the husbands of the intervention group women were interviewed at the pre interview since encouraging their presence at the clinic for an interview would have changed the control conditions at clinics (more men would be present and sensitized by the questions in the interviews). This strategy also helped keep the cost of the study within a manageable level since locating them at home would have been costly.

\section{Women Interviewed}

\section{Study Design}

\begin{tabular}{|c|c|c|}
\hline Experimental group & $\begin{array}{c}\text { ANC } \\
\mathrm{O}_{1} \mathrm{X}_{1}\end{array}$ & $\begin{array}{l}\mathrm{PNC} \\
\mathrm{X}_{2}\end{array}$ \\
\hline Non-equiv. control group & $\begin{array}{l}\text { ANC } \\
\mathrm{O}_{3}\end{array}$ & \\
\hline \multicolumn{3}{|l|}{ Husbands Interviewed } \\
\hline Experimental group & $\mathrm{O}_{1} \mathrm{X}_{1}$ & $\mathrm{X}_{2}$ \\
\hline
\end{tabular}

ANC: Routine antenatal care at ESIC dispensary

$\mathrm{X}_{1}$ : $\quad$ ANC intervention ( 1 individual and 1 couple counseling sessions per couple + routine ANC Services)

$\mathrm{O}_{1}$ : $\quad$ Standardized survey of ANC clients and their husbands at clinic

$\mathrm{O}_{3}$ : $\quad$ Standardized survey of ANC clients at clinic

PNC: Newly added 6 weeks postnatal care clinic at ESIC dispensary

$\mathrm{X}_{2}$ : $\quad$ PNC intervention (postnatal check-up and 1 postpartum couple counseling session + routine Immunization and FP Services)

PP: $\quad 6-9$ months postpartum period

$\mathrm{O}_{2} \quad$ Standardized survey of postpartum women and their husbands at home

$\mathrm{O}_{4} \quad$ Standardized survey of postpartum women and their husbands at home 


\section{Survey Eligibility Criteria}

Women: Women attending ESIC ANC services for an early prenatal visit were enrolled if they met the following criteria:

$>$ Pregnancy between 10-26 weeks of gestation;

> In stable union and both husband and wife expected to be present at same address at six months postpartum;

$>$ Gave informed consent to participate in the study and to have her husband contacted/requested to participate.

Men: All consenting eligible women from the intervention clinics were requested to invite their husbands to join them during the ANC visit if already present at the dispensary, or alternatively, an invitation signed by the provider containing information and requesting his involvement at the next visit was provided to the pregnant woman.

A woman's husband was enrolled in the intervention group when he accompanied his wife to the clinic and gave his consent to:

$>\mathrm{Be}$ interviewed in the clinic during his first joint visit with his pregnant wife;

$>$ Accompany his wife in (at least) one prenatal and one postpartum couple counseling visit;

> Participate in a one-on-one confidential or all-male group counseling session, conducted by a male doctor which usually took place during his first visit to the clinic;

$>$ Be contacted at home when the baby is six months old for another interview.

\section{Sample Size Estimation}

At the time of starting the study NFHS-2 results for Delhi were not available, so the sample size was calculated taking into account the NFHS-1 report estimates of family planning use in Delhi (IIPS and ORC Macro, 1995). Family planning use prior to the intervention was estimated at 40 percent with an expected increase of 15 percent (alpha $=$ 0.05 , and beta at 0.90 percent) at six months postpartum, after the intervention. Sample selection was a two stage process, first selecting participating dispensaries and then selecting women attending the antenatal clinics at dispensaries. Since selection was not random, a correction factor for the design effect needed to be applied. In addition there was relatively high homogeneity of the population in all the six dispensaries, hence a design effect $\mathrm{D}$ of 1.9 was applied. 
The formula applied was:

$$
\begin{gathered}
\mathrm{n}=\left[(\mathrm{Z} \alpha+\mathrm{Z} \beta)^{2}\left(\mathrm{p}_{1} \mathrm{q}_{1}+\mathrm{p}_{2} \mathrm{q}_{2}\right) /\left(\mathrm{p}_{2}-\mathrm{p}_{1}\right)^{2}\right] \mathrm{D} \\
\text { Where } \alpha=.05 \\
\beta=.90 \\
\mathrm{p}_{1}=.40 \\
\mathrm{q}_{1}=.6 \\
\mathrm{p}_{2}=.55 \\
\mathrm{q}_{2}=.45 \\
\mathrm{D}=1.9
\end{gathered}
$$

Using a one-tailed test, the total number to be sampled from both control and intervention groups was estimated to $b e n=338$. Adding an additional 20 percent for loss to follow-up, the sample size estimated was 406 in each group.

\section{Study Site}

Employees' State Insurance Corporation (ESIC) clinics in New Delhi: This study was conducted in six dispensaries in New Delhi operated by the Employees' State Insurance Corporation (ESIC), a national social security organization under the Ministry of Labor, India. The ESIC runs hospitals, stand-alone emergency facilities, diagnostic centers and dispensaries in most states of India. ESIC provides medical care and insurance to enrolled populations (workers earning $<\$ 140$ per month). ESIC is a national organization that is financed by employee and employer and State Government contributions, and no direct fee for service is charged.

In Delhi, ESIC operates five hospitals and 34 dispensaries covering 2.2 million subscribers and their families. Each dispensary is open from 7 am to $7 \mathrm{pm}$, and services are provided in two shifts by four to 10 physicians, auxiliary nurse midwives (ANMs), laboratory technicians, pharmacists and clerical staff. Each dispensary serves a welldefined population of insured persons who choose a particular dispensary nearest their work place or home. Most dispensaries are located in or near low-income residential or industrial areas of Delhi. 
Approximately 60 percent of the caseload in New Delhi's ESIC dispensaries is comprised of men who attend the general out-patient department, although a full range of preventive and curative services are available to children, women and men.

\section{MiM Intervention}

The MiM intervention added the following elements into established routine antenatal and immunization clinics run once a week. The intervention included training providers to conduct brief counseling sessions and behavior change communication (BCC), new IEC materials and some new clinical practices (i.e. universal syphilis screening, syndromic management of self reported UD and GU symptoms, postpartum mother-baby clinic).

Antenatal Care Counseling: ANMs and male and female doctors were expected to include the following topics when counseling women and couples:

$>$ Care and nutrition during maternity including the importance of planning for the birth, recognizing and acting upon the presence of any danger signs during pregnancy/birth/postpartum and making arrangements for transportation to the hospital

$>$ The importance of exclusive breastfeeding to six months and complementary feeding thereafter and its benefits for mother and baby

$>$ Return to fertility and postpartum family planning and the choice of contraceptive methods available including LAM

$>$ Encouraging mother-baby postnatal checkup at six weeks and complete immunizations of infants.

STI preventive counseling: The following content was to be included in single sex groups or individual counseling sessions:

$>$ How STIs are spread, symptoms of urethral discharge and genital ulcers, their effects on the health of the affected person and the unborn child, primary prevention practices (including how to use a condom demonstrated on a penis model) and secondary prevention practices when symptoms occur.

Universal syphilis testing: The reproductive health component included universal syphilis testing (using RPR test) for all pregnant women and appropriate management for those who tested positive (including partner counseling and treatment and risk reduction $\mathrm{BCC}$ as well as condom information, demonstration and supply). 
Provision of STI services and treatment: Husbands attending counseling sessions were to be informed of and asked about signs and symptoms of urethral discharge and genital ulcer disease. If they presented symptoms they were encouraged to report them to the male doctor who was trained in syndromic management of STIs according to national guidelines which include partner's presumptive treatment.

Postpartum care and FP counseling: Couples were encouraged to attend a clinic at six weeks postpartum where the mother and baby would receive a postnatal checkup and couples would be offered a full range of appropriate postpartum contraceptives including both modern and traditional methods (appropriateness refers to breastfeeding and STI risk status).

\section{Implementation of Intervention}

The MiM training for providers took place during November 2000. Two male and two female doctors, a laboratory technician and four ANMs from each of the three intervention dispensaries were trained in family planning and STI counseling. A training manual was developed and a six-day training was held, spread over two weeks, which covered all the components of the intervention. The intervention was integrated into existing ANC services during a brief introductory period in the month of December 2000. Figure 1 below shows the total numbers of ANC clients who attended the clinics during the study period (2000-2002).

The intervention dispensaries began individual and couple counseling and antenatal syphilis screening for pregnant women in January 2001. The pregnant woman would attend her consultation and after consenting to her husband's presence, he would be invited in for a couple counseling consultation that, on average, took six minutes. 
Figure 1: Service statistics from intervention dispensaries

( 2001 and 2002)

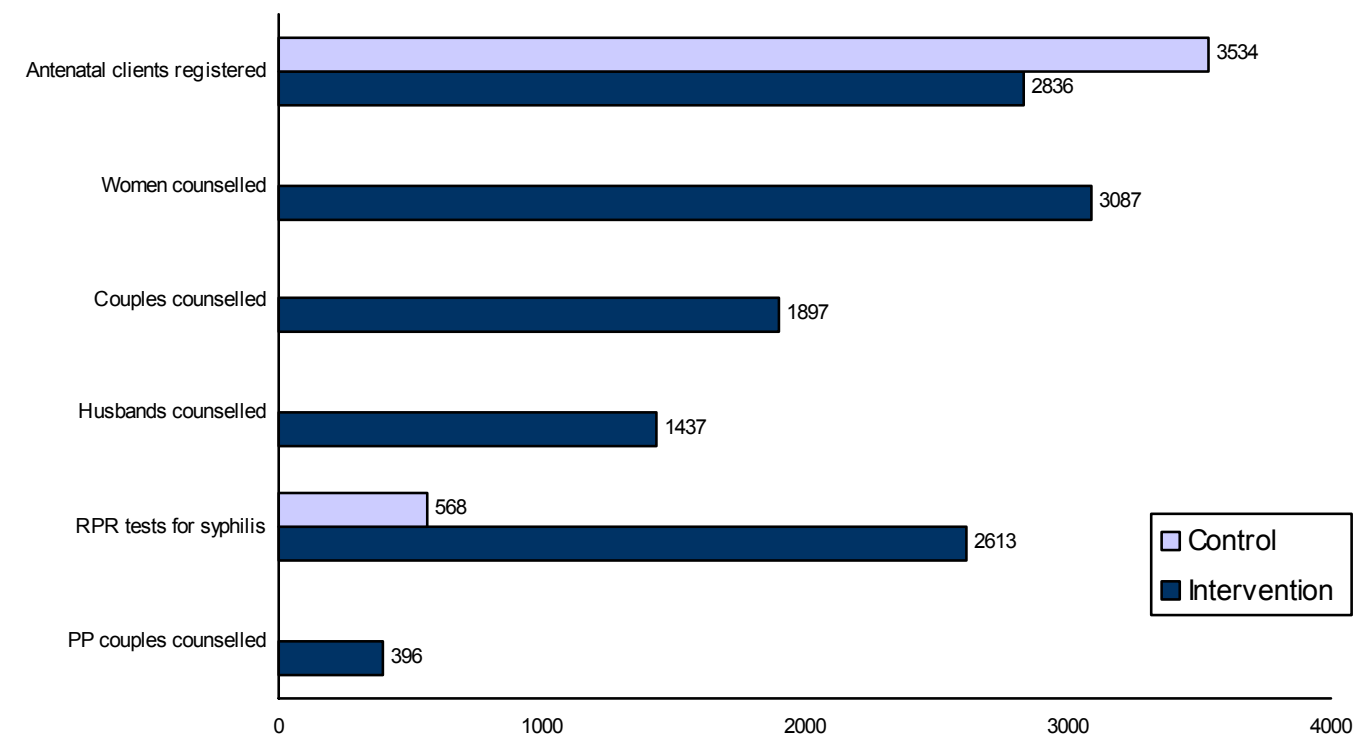

* The total number of women counselled exceeds the number of clients registered because of group counselling sessions and repeated sessions for some women

Using a newly developed maternity card as the primary job aid, ANMs and doctors discussed maternity care and additional components of the MiM intervention with couples and then sent the husband to a male doctor for a short (4 minutes) male-only counseling while the wife was having her examination. The woman also received a short individual counseling session or waited until a group of women collected for group counseling about STIs and condom demonstrations. After a few months all three clinics evolved a routine of at least two sessions of women-only group counseling sessions as they felt that they and the women were more comfortable seeing a condom demonstration in a group than individually; this strategy also saved provider time which was at a premium. The male counseling approach varied based on the male doctors - some continued with individual counseling, some in afternoon sessions, while others conducted all-men group counseling. 


\section{Antenatal Couple Counseling}

The existing recording and reporting system was modified and posters, brochures, and job aids were introduced within the first three months after provider training. Review and refresher meetings continued through the first year (10 review meetings and 2 refresher meetings in 2001 and 5 review meetings and 2 refresher meetings in 2002). The total numbers of clients served throughout the two years of the MiM study, based on monthly clinic reports, continued to remain fairly constant over the two years compared to previous years (See Appendix 1).

\section{Monitoring the Implementation of the MiM Intervention}

Staff of the Population Council visited the three intervention sites at least once a month throughout the two years and provided on-site support and mentoring. The control clinics continued to provide routine antenatal care using the unmodified ESIC antenatal protocol and form. One of the three control dispensaries had been conducting and continued to perform on-site syphilis screening while two others did not. An early evaluation of the services implemented was undertaken in September 2001, using the revised client maternity card as the source of information to improve service quality. The analysis of 300 maternity cards (100 from each intervention dispensary), selected through systematic random sampling, revealed that:

- Only three percent of women registered at the antenatal clinics in the first trimester.

- Each woman made three antenatal visits on average.

- Eighty-five percent of the cards showed that husbands had been present during at least one ANC visit.

- In 90 percent of the records, discussions of a delivery plan and an emergency obstetric plan had been recorded.

- In 93 percent of the records, the RPR test had been ordered; however, only at 2 clinics were 90 percent of the test results recorded. At the third clinic, only 23 percent of the syphilis test results were recorded, though on further investigation it was found that the laboratory RPR register had more complete recording, but that the test results were not being noted in the individual client's maternity card.

- The maternity cards also indicated that for 77 percent of women couple counseling had taken place.

- An equal proportion of women had been counseled (77 percent).

- In 58 percent of the cards the husbands had also been counseled individually. 
- Of the 300 cards reviewed 110 were of women whose expected date of delivery was more than six weeks prior to the review and therefore were a potential postnatal client. Among these women only 16 (14.5 percent) had come for a postnatal checkup with their child, and of these 15 were accompanied by their husbands.

Continued monitoring throughout the study continued and low attendance for postnatal clinics was addressed through a one-day refresher meeting and by suggesting that providers set a specific date with the clients for their postpartum visit. Over time and with repeated emphasis on the importance of attending a postnatal clinic there has been a gradual rise in postnatal clinic attendance at dispensaries.

\section{Behavior Change Communication and Other Materials Supplied}

A maternity care brochure and a brochure on STIs and their prevention were developed to reinforce messages that clients and their husbands received during antenatal visits and were available throughout the study. The Maternity Care Brochure included a page used as a client-held antenatal care record and was given to couples at their first visit. The STI brochure was usually given during the male counseling or to women when their husbands did not attend the clinic. The brochure also contained illustrations that explain the correct use of condoms and the dual protection it provides. It was particularly useful in situations where there was not enough privacy to provide an actual condom demonstration on a penis model. Two penis models were provided to each site to demonstrate how to correctly put on a condom.

The MiM study team also developed five posters for display on clinic walls, on themes that were not covered by other FP and STI/AIDS materials. These were displayed throughout the study only in the intervention dispensaries in waiting areas and inside rooms used for the antenatal and postnatal check-ups. The themes of the five posters were: 1) a man taking on household responsibility; 2) encouraging use of condoms to limit family size; 3) how condoms protect the unborn child from STIs; 4) showing couples can attend antenatal clinics together; and 5) explaining the three conditions of LAM for postpartum family planning. At the start of the intervention each clinic received three sets of 5 posters each as well as 500 maternity cards and Maternity and STI 
brochures; these were restocked on clinics' request. Two RPR kits per clinic were supplied and these were replenished when fewer than 20 tests remained. On the request of providers and after the refresher meetings, family planning check-lists, a syphilis testing and treatment protocol and syndromic management protocols were supplied to the three clinics.

\section{Means to Encourage Husbands Participation}

Providers asked women attending the antenatal clinic if they would like their husband to be invited into the room during their consultation. Women asked their husbands to come into the antenatal room if he was waiting outside. A poster reinforcing this message was prominently displayed on walls in the waiting areas in the general clinic area. If her husband had not accompanied her during this visit, the woman was asked whether she could invite him to accompany her for her next visit. In addition, an invitation letter signed by the doctor in charge of the clinic was given to women inviting their husbands. Among the 581 women interviewed in the intervention group, all women wanted their husbands to participate. Sixty-three percent of the women mentioned that their husbands were present on the day of her interview and another twenty-one percent of husbands agreed to participate in the next ANC visit in response to the verbal and written invitation given by their wives. This took the total to 488 , i.e., 84 percent of husbands participated in the intervention.

\section{Ethical Issues and Informed Consent}

There were two key ethical issues of concern during the MiM Study: that informed consent for participation and confidentiality of information communicated during the intervention would be assured. Since the MiM interventions were clinic-wide interventions that were integrated into routine antenatal and postpartum care of all consenting clients, all antenatal clients visiting an intervention site were offered the MiM services whether or not they were eligible for or agreed to participate in the survey and independent of their husband's involvement. All women were approached first and their permission asked to involve their husbands; their responses were recorded on the 
maternity cards before husbands were invited. Providers and interviewers were trained on issues of confidentiality related to information shared during counseling sessions and interviews, and also on the need to be sensitive to the possibility of spousal violence related to open disclosure. The interviewers were monitored to ensure that the highest standards of voluntary participation in the survey were maintained, and confidential data storage was physically verified.

Informed consent and confidentiality of information during the survey was ensured through the process of consent from all clients and husbands prior to their interviews. Special cardboard partitions were designed and used to ensure visual privacy during interviews and chairs provided for comfort during the 40-45 minute interview. Women's consent to contact their husbands for an interview was first taken before interviewing men in the pre interviews. The same procedure was repeated in the six month postpartum follow-up interview. Completed questionnaires were stored in a locked room after removing all personal individual identifiers; these were stored separately.

\section{Data Collection Procedures}

The pre and post surveys used structured questionnaires for women and men. An independent agency, TNS MODE, conducted the interviews. TNS MODE hired and trained 50 male and female interviewers; from these, 15 men and 19 women were selected as interviewers and five as supervisors, so that interviews could be conducted by same sex interviewers at the weekly ANC clinic. Three male and three female interviewers and three supervisors were retained to conduct the follow-up postpartum interviews at home for the POST survey.

\section{Sampling Procedures}

The estimated total sample size was 450 women at the control clinics and 450 at the intervention clinics. Women in each ANC clinic continued to be screened for eligibility and enrolled until the total sample was met. The survey started simultaneously at all three control ESIC dispensaries in November 2000, and upon completion in May 
2001, began in the three intervention dispensaries. An additional month of data collection at intervention sites was added to ensure that every husband of the women interviewed until November 2001 would have a chance to be interviewed if he came for his wife's next ANC visit.

\section{Sampling Results}

Only 36 percent of the women attending antenatal clinics met the selection criteria and were interviewed. The large number of second or higher order visits for antenatal care and a first visit after 26 weeks of pregnancy were the two main reasons for noneligibility of the remaining 64 percent. Ineligibility because of the possibility that the couple would not be at the same address at 6 months postpartum was nil, and actual refusals to participate in the study for other reasons were less than two percent.

Four hundred eighty-six women in the control group and 581 women in the intervention group were interviewed. Four hundred and eightyeight husbands (84 percent) of the 581 women interviewed in the intervention group completed the pre survey. Forty-five of the 93 (48 percent) men who were not contactable in the pre survey were contacted and interviewed in the post survey. Analysis of the characteristics of the men who were

\section{Figure 2: MiM Sampling Results}

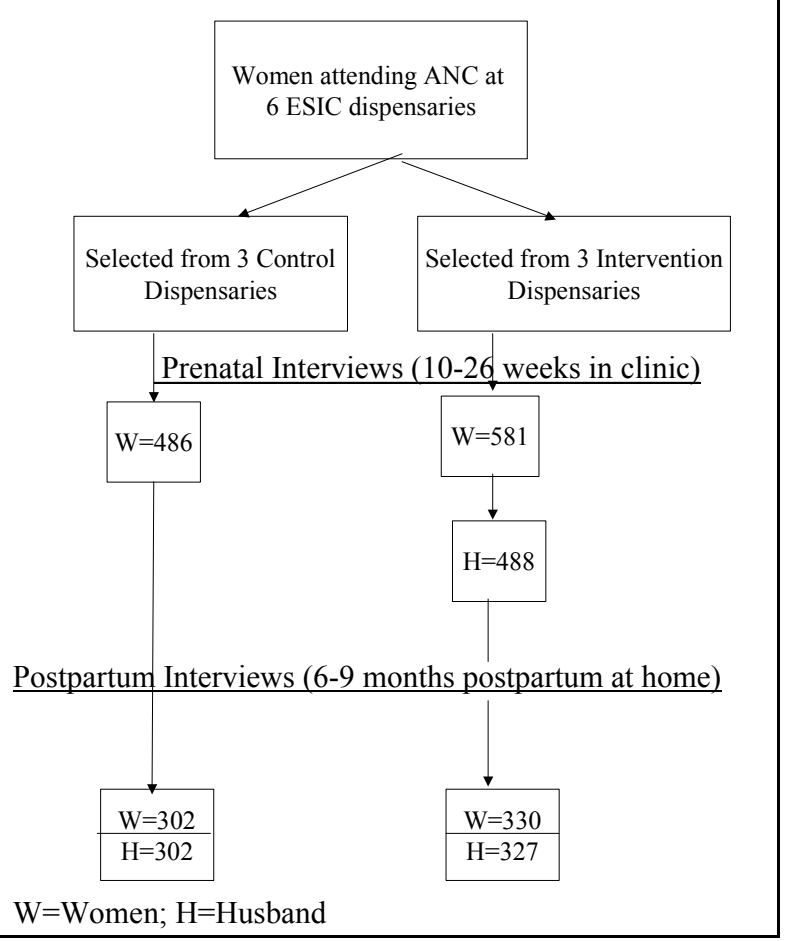
not interviewed at baseline, as reported in the wife's pre interview were similar, except they were slightly older (mean age 29.6 years) than the men who accompanied their wives and were interviewed (mean age 28.3 years). The main reason given for their nonattendance to the ANC clinic was inability to get leave from work. 
The postpartum follow-up survey attempted to contact all women interviewed during pregnancy and, after obtaining their consent, their husbands were tracked for an interview at home between 6 to 9 months postpartum. Loss to follow-up averaged 41 percent and the final number of women whose husbands were also interviewed in the postpartum period was 302 (62 percent) of the original 486 control group interviewed in the pre survey and 327 (56 percent) from the original 581 women from the intervention group.

There were three main reasons responsible for loss of follow-up:

- Wives' or couples' extended postpartum absence from their home accounted for 37 percent and 41 percent of the loss to follow-up in controls and intervention, respectively

- Inability to find the couples' homes due to incomplete or false address, (30 percent and 24 percent)

- Couples who had moved permanently out of town (15 percent and 21 percent)

A series of other reasons accounted for less than 5 percent each.

The researchers were aware of the tradition of women returning to their natal home for confinement or for the early postpartum period and had added this to the eligibility criteria. However, all the women said they would be available at home six months postpartum.

\section{Data Analysis Procedures}

The six ESIC dispensaries selected for the study were purposively selected among clinics with high antenatal clinic attendance, an on-site laboratory and with space for counseling to take place. The distribution into control and intervention clinics among the six selected was done to ensure balanced geographic distribution of sites within Delhi. It was assumed at the time of sampling that the population across all six clinics would be fairly homogenous since ESIC's insurance eligibility criteria are fairly uniform in terms of income bracket and types of occupation covered. This suggested that background and key study indicators across clinics would be fairly similar so that the variance between the study groups' control and intervention clinics would be close to 1. A detailed assessment 
of comparability between intervention and control groups at pre survey on all key variables was carried out and is given in an earlier report (Mishra et al. 2002). The final analysis compared the control and intervention group as a whole and adjusted for any clustering effects.

Three key assumptions in the research design to be tested were:

- That the control and intervention group women are comparable.

- That control men, not interviewed at pre, are comparable to the intervention men who were interviewed.

- That clients and husbands lost to follow-up are similar to those who were interviewed in the post.

The variance estimates used in the statistical tests of differences in outcomes by study groups were adjusted to account for the clustering of study participants within dispensaries. This adjustment consisted of multiplying the variance calculated without clustering by a design effect specific to outcomes of interest. A design effect is a summary measure that reflects an increase in variance of outcomes due to clustering of study participants within the dispensary. The design effect of 2.87 was used to compare the clients across sites, and the design effect of 1.42 has been used to adjust the statistical tests of differences to test the hypotheses. Detailed analysis of the variance is given in Appendix 2. 


\section{Comparison of Control and Intervention Group Women}

The control and intervention group women were similar including the variable parity (see Tables 1 and 2A, below). Comparisons between the intervention and control groups on the number of living children showed that the two groups did not differ significantly on the mean number of living children, 0.92 in the intervention and 1.10 among the control group, and there was a similar trend in the samples across parities.

Table 1: Number of Living Children- Women's Responses from PRE Survey

\begin{tabular}{|l|c|c|}
\hline \hline \multicolumn{1}{|c|}{ Living Children } & $\begin{array}{c}\text { Control } \\
(\mathrm{N}=486)\end{array}$ & $\begin{array}{c}\text { Intervention } \\
(\mathrm{N}=581)\end{array}$ \\
\hline None & 37.8 & 32.7 \\
1 & 39.3 & 36.0 \\
2 & 16.9 & 22.9 \\
3 & 4.9 & 5.9 \\
$4+$ & 1.0 & 2.6 \\
\hline Mean & 0.92 & 1.10 \\
S.D. & 0.913 & 1.04 \\
\hline
\end{tabular}

$t=-1.78, p>0.05$

\section{Comparison of Control and Intervention Group Men at Pre}

Since only the intervention group's husbands were interviewed at the pre survey, this analysis was conducted in two stages. First a comparison of control and intervention women's pre responses about their husbands was conducted for comparability. Second, the intervention group women's reports on husbands were compared with the intervention group men's report about themselves on basic characteristics to see if wives' reports about their husbands were valid.

A comparative analysis of women's responses about husbands and the intervention group's husbands' responses about themselves in the pre were found to be similar, as shown in Table 2A, (columns 3,4 and 5). The assumption at the time of post was therefore that the control and intervention groups were not significantly different and men's responses can be compared at post. 


\section{Comparison of Characteristics of those Lost to Follow-up and those Interviewed at post survey}

The comparison of background characteristics (from pre) of those women who were interviewed in the post and those who were lost to follow-up showed that the women who were lost to follow-up were significantly younger, less educated and less likely to own their house than those interviewed (Table 2A columns 6,7,8,9).

Table 2A: Comparisons of Study Group Characteristics to Test Validity of Sampling Design

\begin{tabular}{|c|c|c|c|c|c|c|c|c|c|}
\hline \multirow{4}{*}{$\begin{array}{l}\text { General } \\
\text { Characteristic as } \\
\text { reported in PRE- } \\
\text { survey by self or } \\
\text { spouse }\end{array}$} & \multicolumn{5}{|c|}{ PRE SURVEY } & \multirow{2}{*}{\multicolumn{4}{|c|}{$\begin{array}{c}\text { PRE SURVEY } \\
\begin{array}{c}\text { Comparing followed-up and lost to } \\
\text { follow-up women }\end{array}\end{array}$}} \\
\hline & \multicolumn{3}{|c|}{$\begin{array}{l}\text { Comparing respondents' } \\
\text { reports about themselves }\end{array}$} & \multicolumn{2}{|c|}{$\begin{array}{c}\text { Comparing } \\
\text { women's reports } \\
\text { about husbands }\end{array}$} & & & & \\
\hline & $\begin{array}{c}\text { Cont. } \\
1\end{array}$ & $\begin{array}{c}\text { Intev. } \\
2\end{array}$ & $\begin{array}{c}\text { Intev. } \\
3 \\
\end{array}$ & $\begin{array}{c}\text { Intev. } \\
4 \\
\end{array}$ & $\begin{array}{c}\text { Cont. } \\
5 \\
\end{array}$ & $\begin{array}{c}\text { Intev. } \\
6 \\
\end{array}$ & $\begin{array}{c}\text { Intev. } \\
7 \\
\end{array}$ & $\begin{array}{c}\text { Cont. } \\
8 \\
\end{array}$ & $\begin{array}{c}\text { Cont. } \\
9\end{array}$ \\
\hline & $\begin{array}{l}\text { Women } \\
(\mathrm{N}=486)\end{array}$ & $\begin{array}{l}\text { Women } \\
(\mathrm{N}=581)\end{array}$ & $\begin{array}{c}\text { Men } \\
(\mathrm{N}=488)\end{array}$ & $\begin{array}{l}\text { Reported } \\
\text { about } \\
\text { husband } \\
(\mathrm{N}=581)\end{array}$ & $\begin{array}{l}\text { Reported } \\
\text { about } \\
\text { husband } \\
(\mathrm{N}=488)\end{array}$ & $\begin{array}{c}\text { Women } \\
\text { interview } \\
\text {-ed } \\
(\mathrm{N}=327)\end{array}$ & $\begin{array}{l}\text { Women } \\
\text { lost to } \\
\text { follow-up } \\
(\mathrm{N}=253)\end{array}$ & $\begin{array}{c}\text { Women } \\
\text { interview } \\
\text {-ed } \\
(\mathrm{N}=302)\end{array}$ & $\begin{array}{l}\text { Women } \\
\text { lost to } \\
\text { follow-up } \\
(\mathrm{N}=184) \\
\end{array}$ \\
\hline Age Distribution & & & & & & & & & \\
\hline $\begin{array}{l}\text { Less than } \\
20\end{array}$ & 7.6 & 7.1 & 0.2 & 0.0 & 0.0 & 5.2 & 9.5 & 7.0 & 8.7 \\
\hline $20-24$ & 53.9 & 48.7 & 15.2 & 11.3 & 14.2 & 48.8 & 48.6 & 49.5 & 60.8 \\
\hline $25-29$ & 29.0 & 34.8 & 47.3 & 48.6 & 46.2 & 36.0 & 33.2 & 25.5 & 31.2 \\
\hline $30-34$ & 8.6 & 8.6 & 27.7 & 30.0 & 27.8 & 9.5 & 7.5 & 4.3 & 11.3 \\
\hline $\begin{array}{l}35 \text { and } \\
\text { above }\end{array}$ & 0.8 & 0.9 & 9.6 & 10.1 & 11.7 & 0.6 & 1.2 & 0.5 & 1.0 \\
\hline Mean Age & 24.0 & 24.2 & 28.70 & 28.5 & 28.5 & 24.5 & $\begin{array}{c}23.9 \\
(z=1.4)\end{array}$ & 24.4 & $\begin{array}{c}\mathbf{2 3 . 2}^{*} \\
(\mathrm{z}=2.22)\end{array}$ \\
\hline Education & & & & & & & & & \\
\hline $\begin{array}{l}\text { No } \\
\text { schooling }\end{array}$ & 33.1 & 35.6 & 7.3 & 7.7 & 8.6 & 30.8 & 41.9 & 30.2 & 38.0 \\
\hline $1-4$ years & 5.1 & 5.5 & 5.7 & 6.2 & 6.0 & 5.5 & 5.5 & 5.0 & 5.4 \\
\hline $\begin{array}{l}5-8 \text { years } \\
9-12 \text { years }\end{array}$ & $\begin{array}{l}26.1 \\
29.0\end{array}$ & $\begin{array}{l}27.9 \\
25.1\end{array}$ & $\begin{array}{l}13.5 \\
46.5\end{array}$ & $\begin{array}{l}12.6 \\
52.5\end{array}$ & $\begin{array}{l}11.9 \\
53.7\end{array}$ & $\begin{array}{l}26.2 \\
29.0\end{array}$ & $\begin{array}{l}30.0 \\
20.2\end{array}$ & $\begin{array}{l}24.3 \\
32.9\end{array}$ & $\begin{array}{l}29.3 \\
22.3\end{array}$ \\
\hline $\begin{array}{l}\text { More than } \\
12 \text { years }\end{array}$ & 6.6 & 5.9 & 26.0 & 21.0 & 19.8 & 8.5 & 2.4 & 7.6 & 5.0 \\
\hline $\begin{array}{l}\text { Median } \\
\text { years of } \\
\text { schooling }\end{array}$ & 7.0 & 5.0 & 10.0 & 10.0 & 10.0 & 7.0 & $\begin{array}{c}5.0^{*} \\
(z=2.29)\end{array}$ & 8.0 & $\begin{array}{l}5.0 \\
(z=1.47)\end{array}$ \\
\hline
\end{tabular}


Contd..

\begin{tabular}{|c|c|c|c|c|c|c|c|c|c|}
\hline \multirow{4}{*}{$\begin{array}{c}\text { General } \\
\text { Characteristic as } \\
\text { reported in PRE- } \\
\text { survey by self or } \\
\text { spouse }\end{array}$} & \multicolumn{5}{|c|}{ 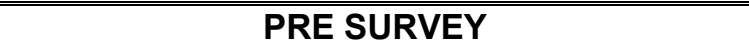 } & \multicolumn{4}{|c|}{ PRE SURVEY } \\
\hline & \multicolumn{3}{|c|}{$\begin{array}{l}\text { Comparing respondents' } \\
\text { reports about themselves }\end{array}$} & \multicolumn{2}{|c|}{$\begin{array}{l}\text { Comparing } \\
\text { women's reports } \\
\text { about husbands }\end{array}$} & \multicolumn{4}{|c|}{$\begin{array}{l}\text { Comparing followed-up and lost to } \\
\text { follow-up women }\end{array}$} \\
\hline & $\begin{array}{c}\text { Cont. } \\
1\end{array}$ & $\begin{array}{l}\text { Intev. } \\
2\end{array}$ & $\begin{array}{l}\text { Intev. } \\
3\end{array}$ & $\begin{array}{l}\text { Intev. } \\
4\end{array}$ & $\begin{array}{l}\text { Cont. } \\
5\end{array}$ & $\begin{array}{l}\text { Intev. } \\
6\end{array}$ & $\begin{array}{c}\text { Intev. } \\
7\end{array}$ & $\begin{array}{c}\text { Cont. } \\
8\end{array}$ & $\begin{array}{c}\text { Cont. } \\
9\end{array}$ \\
\hline & $\begin{array}{l}\text { Women } \\
(\mathrm{N}=486)\end{array}$ & $\begin{array}{l}\text { Women } \\
(\mathrm{N}=581)\end{array}$ & $\begin{array}{c}\text { Men } \\
(\mathrm{N}=488)\end{array}$ & $\begin{array}{l}\text { Reported } \\
\text { about } \\
\text { husband } \\
(\mathrm{N}=581)\end{array}$ & $\begin{array}{l}\text { Reported } \\
\text { about } \\
\text { husband } \\
(\mathrm{N}=488)\end{array}$ & $\begin{array}{c}\text { Women } \\
\text { interview } \\
\text {-ed } \\
(\mathrm{N}=327)\end{array}$ & $\begin{array}{l}\text { Women } \\
\text { lost to } \\
\text { follow-up } \\
(\mathrm{N}=253)\end{array}$ & $\begin{array}{c}\text { Women } \\
\text { interview } \\
\text {-ed } \\
(\mathrm{N}=302)\end{array}$ & $\begin{array}{l}\text { Women } \\
\text { lost to } \\
\text { follow-up } \\
(\mathrm{N}=184)\end{array}$ \\
\hline Reported literate & 64.4 & 62.7 & 84.8 & 91.7 & 91.9 & 67.4 & $\begin{array}{c}56.5 \\
(z=1.61)\end{array}$ & 70.8 & $\begin{array}{c}62.2 \\
(z=1.14)\end{array}$ \\
\hline $\begin{array}{l}\text { Proportion } \\
\text { pregnant for the } \\
\text { first time }\end{array}$ & 29.0 & $\begin{array}{c}23.2 \\
(z=1.27)\end{array}$ & $\begin{array}{c}\text { Not } \\
\text { asked }\end{array}$ & & & 27.0 & $\begin{array}{c}20.0 \\
(z=1.8)\end{array}$ & 27.0 & $\begin{array}{c}32.2 \\
(z=1.2)\end{array}$ \\
\hline $\begin{array}{l}\text { Currently married \& } \\
\text { living with husband }\end{array}$ & 99.6 & 99.5 & 94.5 & & & 100.0 & 99.4 & 99.7 & 99.5 \\
\hline $\begin{array}{l}\text { Own the house } \\
\text { currently living in }\end{array}$ & 39.9 & 41.7 & $\begin{array}{c}\text { Not } \\
\text { asked }\end{array}$ & & & 50.0 & $\begin{array}{c}30.8^{*} \\
(z=2.83)\end{array}$ & 44.5 & $\begin{array}{c}32.6 \\
(z=1.56)\end{array}$ \\
\hline $\begin{array}{l}\text { Currently working } \\
\text { for money }\end{array}$ & 11.5 & 7.7 & 99.4 & & & 9.5 & $\begin{array}{c}5.5 \\
(z=1.09)\end{array}$ & 14.0 & $\begin{array}{c}7.6 \\
(z=1.35)\end{array}$ \\
\hline $\begin{array}{l}\text { Husband provides } \\
\text { financial support }\end{array}$ & 98.1 & 96.9 & 98.2 & & & 96.6 & 97.1 & 98.0 & 97.1 \\
\hline
\end{tabular}

${ }^{*} p<0.05$

\section{General Characteristics}

The MiM study population was defined by the fact that the sample was selected from Delhi's ESIC subscribers or spouses visiting dispensaries for antenatal care in their early pregnancy. A comparison of the characteristics of the intervention and control groups from the pre survey showed that their general background characteristics were similar. The mean age of women enrolled was 24 years and their husbands' age was 29 years. Most women were not employed outside the home and a third had little or no formal school education.

\section{Standard of Living}

Data on items on standard of living showed that there was no significant difference between the intervention and control groups. These statistics indicate that the two groups matched well with respect to their socio-economic background.

Housing: Eighty percent of the respondents lived in houses built with brick and cement, 90 percent with electricity, 77 percent with running water and 70 percent with toilets. Forty percent of the women reported that the family owned their houses; the rest 
lived in rented accommodations or houses provided by an employer. Three quarters of women from the control group and 71 percent of women from the intervention group reported that there was only one sleeping room in their house and 82 percent of women from both groups reported that three or more members lived in the household. These statistics reflect the crowded conditions in most houses.

Household possessions: Questions were asked regarding possession of some durable goods. Seventy-nine percent of the control group and 83 percent of the intervention group reported having a television or radio. Telephones were present in the homes of 14 percent of the control group and 12 percent of the intervention group. The most common modes of transport owned by the household were bicycles (43 percent in both the groups), followed by a motorcycle or scooter (13 and 11 percent in the control and intervention group, respectively).

A comparison of some key outcome measures at the pre survey was assessed based upon whether the women could be interviewed in post survey or not (Table 2B) in intervention and control groups. The women who could be followed-up had also reported higher ever-use of family planning and had shown greater intention to use family planning after the birth of the index child than those lost to follow-up, but these differences were not significant.

Because of these significant differences in basic characteristics and key outcome indicators, the post survey comparisons were only made for the sample that had completed both a pre and a post interview. 
Table 2B: Comparisons of Study Group Characteristics on Key Outcome Indicators at PRE Survey by Follow-up Status in POST Survey

\begin{tabular}{|c|c|c|c|c|}
\hline \multirow[b]{3}{*}{$\begin{array}{l}\text { Key outcome indicators as } \\
\text { reported by women at PRE survey }\end{array}$} & \multicolumn{4}{|c|}{ Women in PRE Survey } \\
\hline & \multicolumn{2}{|c|}{ Control } & \multicolumn{2}{|c|}{ Intervention } \\
\hline & $\begin{array}{c}\text { \% Followed- } \\
\text { up } \\
(\mathrm{N}=302)\end{array}$ & $\begin{array}{c}\% \text { Not } \\
\text { followed- } \\
\text { up } \\
(\mathrm{N}=184)\end{array}$ & $\begin{array}{c}\text { \%ollowed- } \\
\text { up } \\
(\mathrm{N}=327) \\
\end{array}$ & $\begin{array}{c}\% \text { Not } \\
\text { followed-up } \\
(N=254)\end{array}$ \\
\hline Inter-spousal communication on FP & 55.5 & 51.5 & 54.9 & 49.0 \\
\hline Know any danger sign in pregnancy & 19.6 & 20.7 & 8.1 & 12.4 \\
\hline Heard of STIs & 33.2 & 25.0 & 34.1 & 24.1 \\
\hline Heard of HIVIAIDS & 60.8 & 51.6 & 56.4 & $\begin{array}{c}38.3^{*} \\
(z=2.60)\end{array}$ \\
\hline $\begin{array}{l}\text { Know condom as FP method that } \\
\text { protects against STIs/HIV }\end{array}$ & 47.3 & 37.4 & 58.1 & 50.5 \\
\hline Ever used condoms with husband & 30.8 & $\begin{array}{c}17.8^{*} \\
(z=-1.98)\end{array}$ & 27.9 & 19.8 \\
\hline Ever used FP method & 28.2 & 22.3 & 25.9 & 23.7 \\
\hline Intend to use FP after child birth & 64.8 & 55.4 & 37.2 & 36.8 \\
\hline
\end{tabular}

\section{Testing Statistical Significance}

Considering that the study follows a non-equivalent case control design, nonparametric tests have been used to test for significant differences. To test whether a difference in proportions within the control and intervention group was statistically significant, such as when controlling for parity, the Chi-square test for comparison of proportions was used. When differences between the control and intervention group on outcome measures were assessed in the post survey the statistical test of significance used was the Mann-Whitney U Test (often termed as a distribution free test and appropriate for both large and small samples).

In all cases, the statistical tests were specifically used to accept or reject the alternative hypotheses that there was a positive association of outcome with the intervention (Campbell and Machin, 1999). The results were reported significant only if the alpha was less than or equal to 0.05 using a one-sided test. The significance levels given in tables have only been reported with the Chi-square or z-scores, when the two groups differed significantly at 0.05 or lower levels on the respective indicator. 


\section{RESULTS}

This section presents analyses to test the eight study hypotheses. It describes the impact of the intervention on attitudes and behavior changes by comparing post responses on the same questions between intervention and control groups. When assessing changes in knowledge only, women's data are used to examine pre - post differences; knowledge variables are compared between intervention and control groups.

The Null hypothesis $\left(\mathrm{H}_{\mathrm{o}}\right)$ for all the eight hypotheses is that there will be no difference in the control and intervention groups on the outcomes measured. If the differences are statistically significant the alternate hypothesis $\left(\mathrm{H}_{1}\right)$ is accepted, but if the results fail to reach statistically significant levels, or the information is inconclusive the hypothesis is not accepted.

\section{Participation in the Intervention}

Women were enrolled in the sample if they were between 10-26 weeks pregnant. The mean gestation at enrollment was 18 weeks. This early enrolment was designed so that couples had the possibility of full exposure to the intervention. Based on a review of 300 randomly selected maternity cards from the intervention clinics, each woman made an average of three antenatal care visits to the dispensary.

Responses in the post survey to the question "How many times did the provider have discussions with you during pregnancy?" ranged from one to five times in the intervention group. A few of the control group men and women also reported discussions but this was a much smaller number. Results of the analysis of the coverage of the intervention among women and men are shown in Table 3 below. Significant increases were seen on many discussion topics by the intervention women, but the levels still remain below 50 percent for most indicators. This table indicates the need for closer monitoring of services and providers to ensure that counseling includes all important issues. 
Table 3: Level of Participation in Intervention - POST Survey

\begin{tabular}{|c|c|c|c|c|c|c|}
\hline \multirow[b]{2}{*}{$\begin{array}{l}6 \text { months Postpartum } \\
\text { Findings }\end{array}$} & \multicolumn{2}{|c|}{ Women } & \multirow{2}{*}{$\begin{array}{c}\text { z- } \\
\text { statistic }\end{array}$} & \multicolumn{2}{|c|}{ Men } & \multirow{2}{*}{$\begin{array}{c}\text { z- } \\
\text { statistic }\end{array}$} \\
\hline & $\begin{array}{l}\text { Control } \\
(\mathrm{N}=302)\end{array}$ & $\begin{array}{c}\text { Intev. } \\
(\mathrm{N}=327)\end{array}$ & & $\begin{array}{l}\text { Control } \\
(\mathrm{N}=302)\end{array}$ & $\begin{array}{l}\text { Intev. } \\
(\mathrm{N}=327)\end{array}$ & \\
\hline $\begin{array}{l}\text { Had discussions with providers at } \\
\text { any time during maternity care }\end{array}$ & 20.9 & 58.1 & $8.67^{*}$ & 5.6 & 40.7 & $9.73^{*}$ \\
\hline $\begin{array}{l}\text { Provider discussed breastfeeding } \\
\text { during antenatal visit }\end{array}$ & 7.3 & 20.2 & $4.04^{*}$ & 11.9 & 19.9 & $2.32^{*}$ \\
\hline $\begin{array}{l}\text { Provider discussed breastfeeding } \\
\text { as contraceptive during maternity } \\
\text { care }\end{array}$ & 5.6 & 32.1 & $7.15^{*}$ & 2.6 & 15.0 & $4.77^{*}$ \\
\hline $\begin{array}{l}\text { Provider talked about plans for } \\
\text { delivery during antenatal visit }\end{array}$ & 14.6 & 23.2 & $2.33^{*}$ & \multicolumn{3}{|c|}{ Not asked } \\
\hline $\begin{array}{l}\text { Provider talked to both spouses } \\
\text { together during maternity care }\end{array}$ & 1.7 & 26.8 & $7.44^{*}$ & 2.0 & 20.5 & $6.02^{*}$ \\
\hline Provider demonstrated condom use & 4.0 & 40.1 & $8.99^{*}$ & 1.0 & 20.2 & $6.61^{*}$ \\
\hline $\begin{array}{l}\text { Received any information material } \\
\text { from dispensary during maternity } \\
\text { care }\end{array}$ & 1.0 & 73.1 & $15.59^{*}$ & 7.6 & 30.0 & $6.35^{*}$ \\
\hline $\begin{array}{l}\text { Provider discussed FP in antenatal } \\
\text { period }\end{array}$ & 19.2 & 60.6 & $9.83^{*}$ & 6.3 & 45.3 & $10.58^{*}$ \\
\hline $\begin{array}{l}\text { FP information from providers to } \\
\text { users (percent of total) }\end{array}$ & $\begin{array}{l}\mathbf{n}=123 \\
(40.7)\end{array}$ & $\begin{array}{l}\mathbf{n = 1 7 6} \\
(53.8)\end{array}$ & & $\begin{array}{l}\mathbf{n = 1 3 4} \\
(44.4)\end{array}$ & $\begin{array}{l}\mathbf{n = 2 0 0} \\
(61.2)\end{array}$ & \\
\hline How the method works & 18.7 & 45.5 & $4.36^{*}$ & 11.9 & 23.0 & $2.27^{*}$ \\
\hline How to use the method accepted & 16.3 & 46.0 & $4.95^{*}$ & 12.7 & 22.5 & $1.99^{*}$ \\
\hline $\begin{array}{l}\text { What to do if experience side } \\
\text { effects }\end{array}$ & 16.3 & 44.3 & $4.67^{*}$ & 12.7 & 13.5 & N.S. \\
\hline Options in case of side effects & 15.4 & 42.6 & $4.60^{*}$ & 7.5 & 11.0 & N.S. \\
\hline
\end{tabular}

${ }^{*} p<0.05, \quad$ N.S. Not Significant

Forty-three percent of women and 46 percent of husbands reported that their spouse visited the dispensary for a postpartum check-up. This suggests that couples defined postnatal visits differently from the services provided where the visit was defined as postnatal only if it included mother and baby and took place within six weeks of birth.

The term "counseling" is not understood by clients so the questionnaire used the word "discussion" to best describe the process of counseling, as shown in Tables 3 and 4. Table 4 shows that providers discussed family planning more frequently with couples within the intervention group than in the control group.

However, the proportion mentioning such discussions was well below the desired 100 percent. This remained the case even after controlling for parity (Table 4). 
Table 4: Discussion on Family Planning with Providers at Antenatal and Postnatal Visits - POST Survey

\begin{tabular}{|c|c|c|c|c|c|c|}
\hline \multirow{3}{*}{ Family Planning discussions } & \multicolumn{6}{|c|}{ Women } \\
\hline & \multicolumn{3}{|c|}{ With one living child } & \multicolumn{3}{|c|}{ With 2 or more living children } \\
\hline & Control & Intev. & $\begin{array}{c}\text { Z- } \\
\text { statistic }\end{array}$ & Control & Intev. & $\begin{array}{c}\text { Z- } \\
\text { statistic }\end{array}$ \\
\hline Providers discussed in AN period & $\begin{array}{l}11.1 \\
108\end{array}$ & $\begin{array}{c}62.4 \\
93\end{array}$ & $7.31^{*}$ & $\begin{array}{l}23.9 \\
188\end{array}$ & $\begin{array}{l}60.4 \\
222\end{array}$ & $6.76^{*}$ \\
\hline Providers discussed in PN period & $\begin{array}{c}10.2 \\
59 \\
\end{array}$ & $\begin{array}{c}35.9 \\
39 \\
\end{array}$ & $2.47^{* *}$ & $\begin{array}{r}25.9 \\
112 \\
\end{array}$ & $\begin{array}{c}29.0 \\
93 \\
\end{array}$ & N.S. \\
\hline & \multicolumn{6}{|c|}{ Men } \\
\hline Providers discussed in AN period & $\begin{array}{r}1.9 \\
107\end{array}$ & $\begin{array}{c}48.9 \\
90\end{array}$ & $7.21^{*}$ & $\begin{array}{r}9.0 \\
188\end{array}$ & $\begin{array}{l}42.5 \\
226\end{array}$ & $7.20^{*}$ \\
\hline Providers discussed in PN period & $\begin{array}{c}11.5 \\
61\end{array}$ & $\begin{array}{c}20.5 \\
39\end{array}$ & N.S. & $\begin{array}{l}19.6 \\
102\end{array}$ & $\begin{array}{c}11.8 \\
85\end{array}$ & N.S. \\
\hline
\end{tabular}

${ }^{*} p<0.05$, N.S. Not significant. Analysis excludes women currently with no living children

\section{Obstetric History and Birth Outcomes}

Data from the pre survey showed that the proportion of women who were pregnant for the first time was 29 percent, seven percent reported having had an induced abortion and 26 percent reported a miscarriage in the past. Analysis shows poor spacing between births. Of the women who had at least one living child, a large proportion (49 percent control and 55 percent intervention) had a child aged 24 months or less. This is of concern as it is known that short birth intervals increase the risk of infant mortality.

Table 5: Outcome of Index Pregnancy - POST Survey

\begin{tabular}{|c|c|c|c|c|}
\hline \hline $\begin{array}{c}\mathbf{6} \text { months Postpartum } \\
\text { Findings }\end{array}$ & $\begin{array}{c}\text { Control } \\
\text { Women (\%) } \\
(\mathrm{N}=302)\end{array}$ & Freq. & $\begin{array}{c}\text { Intervention } \\
\text { Women (\%) } \\
(\mathrm{N}=328)\end{array}$ & Freq. \\
\hline $\begin{array}{c}\text { Outcome of last pregnancy } \\
\text { Baby currently living }\end{array}$ & 91.4 & 276 & 93.6 & 306 \\
Baby died $\leq 7$ days & 0.0 & 0 & 0.6 & 2 \\
Baby died > 7 days & 2.0 & 6 & 1.8 & 6 \\
Still Birth & 2.0 & 6 & 1.5 & 5 \\
Miscarriage & 2.6 & 8 & 2.1 & 7 \\
Induced abortion & 2.0 & 6 & 0.3 & 1 \\
\hline Sex of live born baby & & & & \\
Male & 55.0 & 155 & 59.2 & 186 \\
Female & 45.0 & 127 & 40.8 & 128 \\
\hline Live births & 100.0 & $\mathbf{2 8 2}$ & 100.0 & $\mathbf{3 1 4}$ \\
\hline \hline
\end{tabular}

Table 5 shows that no significant differences were found between the control and intervention groups on the outcome of their index pregnancy. In both groups approximately one-third of the interviewed women delivered at home while the rest 
reported a hospital birth; this probably underestimates the number of home deliveries as many of the women who were not interviewed at POST due to prolonged absence from their Delhi home had probably delivered at their parents' home. The imbalance in the proportion of male to female infants born live is noteworthy.

In both the intervention and control groups, approximately six percent of women interviewed at 6-9 months postpartum were pregnant or suspected that they might be pregnant at the time of postpartum interview. Table 6 reveals that this proportion was significantly higher among both control and intervention women who had lost the index pregnancy baby.

Table 6: Proportion of Women who are or may be Pregnant at POST Survey by the Survival Status of Index Pregnancy

\begin{tabular}{|c|c|c|c|c|}
\hline \multirow[b]{3}{*}{ Pregnancy status } & \multicolumn{4}{|c|}{ Women (\%)* } \\
\hline & \multicolumn{2}{|c|}{ Control } & \multicolumn{2}{|c|}{ Intervention } \\
\hline & $\begin{array}{l}\text { Living child } \\
(N=276)\end{array}$ & $\begin{array}{l}\text { Spon. Abor.I } \\
\text { did not } \\
\text { survive } \\
(\mathrm{N}=20)\end{array}$ & $\begin{array}{l}\text { Living } \\
\text { child } \\
(\mathrm{N}=306)\end{array}$ & $\begin{array}{c}\text { Spon. } \\
\text { Abor.l } \\
\text { did not } \\
\text { survive } \\
(\mathrm{N}=20)\end{array}$ \\
\hline $\begin{array}{l}\text { Whether pregnant at the time of } \\
\text { POST survey? } \\
\text { Yes or think so } \\
\text { No }\end{array}$ & $\begin{array}{r}3.3 \\
96.7\end{array}$ & $\begin{array}{c}35.0^{* * *} \\
65.0\end{array}$ & $\begin{array}{r}5.9 \\
94.1\end{array}$ & $\begin{array}{c}25.0^{* *} \\
75.0\end{array}$ \\
\hline & \multicolumn{2}{|c|}{$\left(\chi^{2}=36.7, d f=1, p<0.001\right)$} & \multicolumn{2}{|c|}{$\left(\chi^{2}=10.5, d f=1, p<0.01\right)$} \\
\hline
\end{tabular}

* excludes 7 women who reported an induced abortion

\section{Results of the Hypotheses Tested}

The eight hypotheses were tested mainly through a comparison of self-reports of control and intervention group women and men interviewed using a structured questionnaire at pre and a similar questionnaire at post.

Hypothesis 1: Exposure to the intervention will have a positive effect on men and women's knowledge of family planning and contraceptive practices at six months postpartum. 
Family planning knowledge and intention: The hypothesis on family planning

knowledge was operationalized to include the following variables:

1. Knowledge that breastfeeding can prevent pregnancy; and

2. Knowledge of condoms, and that condoms provide dual protection.

The statistical significance in knowledge difference was analyzed based on the net change in women and men's knowledge from pre to post survey in the control and the intervention groups. Results show (Table 7) that change in knowledge that breastfeeding can prevent pregnancy was significantly higher in the intervention group compared to the control group. The net change in women's knowledge that condoms provide dual protection was not significant between the control and intervention groups. Virtually all women continue to be ignorant about lactational amenorrhoea (LAM) and a large majority do not know of condoms as a means of dual protection.

Table 7: Family Planning Knowledge -Control and Intervention Women in PRE and POST Surveys

\begin{tabular}{|c|c|c|c|c|c|c|}
\hline \multirow{3}{*}{$\begin{array}{l}\text { Family planning } \\
\text { knowledge }\end{array}$} & \multirow{2}{*}{\multicolumn{2}{|c|}{$\begin{array}{l}\text { PRE (\%) } \\
\text { Women }\end{array}$}} & \multicolumn{4}{|c|}{ POST (\%) } \\
\hline & & & \multicolumn{2}{|c|}{ Women } & \multicolumn{2}{|c|}{ Men } \\
\hline & $\begin{array}{l}\text { Control } \\
(\mathrm{N}=302)\end{array}$ & $\begin{array}{c}\text { Intev. } \\
(\mathrm{N}=327)\end{array}$ & $\begin{array}{l}\text { Control } \\
(\mathrm{N}=302)\end{array}$ & $\begin{array}{c}\text { Intev. } \\
(\mathrm{N}=327)\end{array}$ & $\begin{array}{l}\text { Control } \\
(\mathrm{N}=302)\end{array}$ & $\begin{array}{c}\text { Intev. } \\
(\mathrm{N}=327)\end{array}$ \\
\hline $\begin{array}{l}\text { Know breastfeeding can } \\
\text { provide contraception }\end{array}$ & 12 & 8 & 13 & $\begin{array}{c}20^{*} \\
(z=4.89)\end{array}$ & 15 & $\begin{array}{c}22^{*} \\
(z=1.95)\end{array}$ \\
\hline $\begin{array}{l}\text { Know three conditions of } \\
\text { LAM }\end{array}$ & 0 & 0 & 0 & 0 & 0 & 1 \\
\hline $\begin{array}{l}\text { Know condoms as dual } \\
\text { protection }\end{array}$ & 22 & 29 & 38 & $\begin{array}{c}48 \\
(z=0.83)\end{array}$ & 80 & $\begin{array}{c}89^{*} \\
(z=2.62)\end{array}$ \\
\hline
\end{tabular}

${ }^{*} p<0.05, \quad z$-statistics is calculated on pre-post differences of control and intervention women.

Comparing men and women's knowledge, men's knowledge was higher than women's knowledge in general. However, only three men from the intervention group were able to mention the three conditions of LAM and none of the women in either experimental or control group had knowledge of all the three conditions of LAM.

Contraceptive use and intention to use: The hypothesis measured contraceptive use in the postpartum period by asking the following questions in the POST survey:

1. Are you currently using a family planning method?

2. What method are you using?

3. Do you intend to use family planning in the future (among non users)? 
Table 8A: Current Use of Family Planning, Pattern of Use and Intention to UsePOST Survey.

\begin{tabular}{|c|c|c|c|c|}
\hline \multirow[b]{2}{*}{ Family Planning } & \multicolumn{2}{|c|}{ Women (\%)* } & \multicolumn{2}{|c|}{ Men $(\%)^{*}$} \\
\hline & $\begin{array}{l}\text { Control } \\
(\mathrm{N}=269)\end{array}$ & $\begin{array}{l}\text { Intev. } \\
(\mathrm{N}=289)\end{array}$ & $\begin{array}{l}\text { Control } \\
(\mathrm{N}=270)\end{array}$ & $\begin{array}{c}\text { Intev. } \\
(\mathrm{N}=293)\end{array}$ \\
\hline \multirow{4}{*}{$\begin{array}{l}\text { Currently using any FP method } \\
\text { Yes } \\
\text { No }\end{array}$} & & & & \\
\hline & 45.0 & $58.5^{*}$ & 47.8 & $64.5^{\star}$ \\
\hline & 55.0 & 41.5 & 52.2 & 35.5 \\
\hline & \multicolumn{2}{|c|}{$z=2.70, p<0.05$} & \multicolumn{2}{|c|}{$z=3.39, p<0.05$} \\
\hline Method & & & & \\
\hline Female sterilization & 14.9 & 11.2 & 13.2 & 9.5 \\
\hline Oral contraceptives & 6.6 & 9.4 & 6.2 & 7.9 \\
\hline CU-T / IUD & 8.3 & 8.2 & 7.8 & 6.9 \\
\hline Condom & 66.1 & 65.9 & 71.4 & 71.3 \\
\hline Other (Injection, jelly) & 2.5 & 1.2 & 0.7 & 0.5 \\
\hline Natural/traditional methods & 1.6 & 4.1 & 0.7 & 3.7 \\
\hline \multicolumn{5}{|l|}{$\begin{array}{l}\text { Baby's Age when started using } \\
\text { method }\end{array}$} \\
\hline Less than 3 months & 30.6 & 39.4 & 33.6 & 32.6 \\
\hline 3-4 months & 44.6 & 35.9 & 46.3 & 41.7 \\
\hline 5-6 months & 21.5 & 18.2 & 15.7 & 17.0 \\
\hline More than 6 months & 3.3 & 6.5 & 4.5 & 6.5 \\
\hline Don't remember/don't know & 0.0 & 0.0 & 0.0 & 2.0 \\
\hline Mean age of child (months) & 3.2 & 3.3 & 3.2 & 3.6 \\
\hline Men/women reported using FP & 121 & 169 & 129 & 189 \\
\hline $\begin{array}{l}\text { Number not using FP and not pregnant } \\
\text { Intention to use FP in future among } \\
\text { current non-users }\end{array}$ & $\begin{array}{c}160 \\
65.6\end{array}$ & $\begin{array}{c}131 \\
84^{*} \\
(z=3.12)\end{array}$ & $\begin{array}{c}154 \\
61\end{array}$ & $\begin{array}{c}113 \\
71.9 \\
(z=1.58)\end{array}$ \\
\hline
\end{tabular}

The analysis of postpartum family planning use required that those pregnant or suspecting a pregnancy, and those who reported that they had had a spontaneous abortion or lost the index pregnancy be removed from the denominator since they would confound the analysis. Analysis was done separately for those with a living child.

The proportion of respondents ever having used contraceptives was not significantly different between groups at the pre ( 25 percent of intervention and 28 percent control women reported ever use). The analysis on postpartum use of family planning (Table $8 \mathrm{~A}$ ) revealed that a significantly higher proportion of men and women in the intervention group reported using a family planning method postpartum than in the control group. This holds even after controlling for parity (Table 8B) among all men and among women with two or more children. There was no difference between intervention 
and control groups in contraceptive mix, or in the time of starting use of the method. More than half of the postpartum family planning users were using condoms and most began use shortly after the child was three months old.

Family planning intention: Intention to use a family planning method among women not currently using any method and not pregnant was significantly higher among the intervention group. A similar pattern was found among men, however this difference was not significant.

Table 8B: Current Family Planning Use by Parity- POST Survey

\begin{tabular}{|c|c|c|c|c|}
\hline \multirow{3}{*}{ FP Use } & \multicolumn{4}{|c|}{ Women (\%) } \\
\hline & \multicolumn{2}{|c|}{ With one living child } & \multicolumn{2}{|c|}{$\begin{array}{l}\text { With } \geq 2 \text { living } \\
\text { children }\end{array}$} \\
\hline & Control & Intev. & Control & Intev. \\
\hline \multirow{5}{*}{$\begin{array}{l}\text { Currently using any FP method } \\
\text { Yes } \\
\text { No }\end{array}$} & & & & \\
\hline & 45.6 & 60.8 & 45.2 & $54.5^{*}$ \\
\hline & 54.4 & 39.2 & 54.8 & 45.5 \\
\hline & 90 & 74 & 177 & 205 \\
\hline & \multicolumn{2}{|c|}{$z=1.64$} & \multicolumn{2}{|c|}{$z=2.01$} \\
\hline FP method currently used & & & & \\
\hline Female sterilization & 0.0 & 0.0 & 22.5 & 16.1 \\
\hline Oral contraceptives & 7.3 & 6.7 & 6.3 & 11.0 \\
\hline CU-T / IUD & 12.2 & 8.9 & 6.3 & 7.6 \\
\hline Condom & 75.7 & 82.2 & 61.1 & 60.2 \\
\hline Other (Injection, jelly) & 2.4 & 0.0 & 2.5 & 1.7 \\
\hline Natural/traditional methods & 2.4 & 2.2 & 1.3 & 3.4 \\
\hline $\mathbf{N}=$ & 41 & 45 & 80 & 112 \\
\hline & \multicolumn{4}{|c|}{ Men (\%) } \\
\hline \multirow{5}{*}{$\begin{array}{l}\text { Currently using any FP method } \\
\text { Yes } \\
\text { No }\end{array}$} & & & & \\
\hline & 41.3 & $61.3^{*}$ & 51.1 & $65.6^{*}$ \\
\hline & 58.7 & 38.7 & 48.9 & 34.4 \\
\hline & 92 & 75 & 178 & 209 \\
\hline & \multicolumn{2}{|c|}{$z=2.19$} & \multicolumn{2}{|c|}{$z=2.44$} \\
\hline FP method currently used & & & & \\
\hline Female sterilization & 0.0 & 0.0 & 18.7 & 13.2 \\
\hline Oral contraceptives & 5.3 & 4.3 & 6.6 & 8.0 \\
\hline CU-T / IUD & 15.8 & 4.3 & 4.4 & 8.0 \\
\hline Condom & 78.9 & 84.9 & 68.1 & 67.2 \\
\hline Other (Injection, jelly) & 0.0 & 0.0 & 1.1 & 0.7 \\
\hline \multirow[t]{2}{*}{ Natural/traditional methods } & 0.0 & 6.5 & 1.1 & 2.9 \\
\hline & 38 & 46 & 91 & 137 \\
\hline
\end{tabular}

${ }^{*} p<0.05$ 
Use of condoms: Both men and women from the intervention group reported a higher proportion of ever using condoms in the post survey (69 percent men and 54 percent women) compared to 61 percent of men and 45 percent of women from the control group but this difference was not statistically significant $\left(\mathrm{z}_{\mathrm{w}}=1.86 \mathrm{p}>0.05\right)$ and $\left(\mathrm{z}_{\mathrm{m}}=1.88 \mathrm{p}>0.05\right)$. Consistency of condom use was significantly higher among the intervention group men and women who reported using condoms more frequently than the control group $\left(\mathrm{z}_{\mathrm{w}}=3.01 \mathrm{p}<0.05\right)$ and $\left(\mathrm{z}_{\mathrm{m}}=3.41, \mathrm{p}<0.05\right)$. More men and women from the intervention group reported that they jointly decided to use the condom (78 percent of intervention women, vs. 59 percent of controls, $\mathrm{z}_{\mathrm{w}}=3.04 \mathrm{p}<0.05$ and 87 percent of intervention men vs. 77 percent of controls, $\left.\mathrm{z}_{\mathrm{m}}=2.32, \mathrm{p}<0.05\right)$. Comparisons on ever use of condoms between the pre and post women's surveys suggest that the intervention led to a significantly larger number of couples in the intervention group having used the condom (32 percent) in the postpartum period than in the control group (23 percent). This information is corroborated by results from the intervention group men's survey; there was an increase of 33 percent in condom use among men in the postpartum period.

There were few reported problems with condom use, eight percent of men and three percent of women reported problems. The problems mentioned were: diminished pleasure, condoms burst, and allergic reactions to latex.

Satisfaction with family planning method choice: More than 90 percent of FP users at the time of the post were satisfied with their current family planning method, and among the 12 women and 13 men who reported dissatisfaction, most planned to switch to another method.

Table 9: Satisfaction with Current Family Planning Method - POST Survey

\begin{tabular}{|l|c|c|c|c|}
\hline \multirow{2}{*}{ Satisfied with the current method } & \multicolumn{2}{|c|}{ Women (\%) } & \multicolumn{2}{c|}{ Men (\%) } \\
\cline { 2 - 5 } Yes & Control & Intev. & Control & Intev. \\
No & & & & \\
Current users & 93.4 & 97.7 & 95.3 & 96.3 \\
\hline \hline
\end{tabular}




\section{Hypothesis 2: Exposure to the intervention will have a positive effect on men and women's STI preventive behaviors at six months postpartum.}

Changes in STI preventive behaviors are influenced by knowledge. Hence, knowledge levels are presented first to highlight the low levels of understanding of STIs and HIV/AIDS suggesting that behavior change would be less likely to be practiced. Knowledge of STIs and HIV/AIDS was assessed through questions about having ever heard of STIs, their symptoms, modes of transmission and their prevention, as well as any personal history of symptoms and treatment.

STI and HIV/AIDS knowledge and behavior: Knowledge of STIs was low at baseline and continued to be low among men (66 percent) and women (32 percent) at post. Although more men and women in the intervention group had heard of STIs than in the control group, in the pre survey these differences were not statistically significant.

A series of statements were used to assess clients' knowledge of HIV/AIDS protective behaviors. The same questions were asked in the pre and post survey. The analysis showed that increase in knowledge between the control and intervention groups on STIs was small and did not reach statistical significance. The higher levels of awareness of HIV/AIDS than of STIs suggests that mass media campaigns by the national and state AIDS control programs on HIV/AIDS prevention have succeeded in raising awareness.

\section{Table 10: STIs and HIVIAIDS Knowledge - POST Survey}

\begin{tabular}{|l|c|c|c|c|}
\hline \multirow{2}{*}{ Particulars } & \multicolumn{2}{c|}{ Women (\%) } & \multicolumn{2}{c|}{ Men (\%) } \\
\cline { 2 - 5 } & $\begin{array}{c}\text { Control } \\
\text { Post } \\
(\mathrm{N}=302)\end{array}$ & $\begin{array}{c}\text { Intev. } \\
\text { Post } \\
(\mathrm{N}=327)\end{array}$ & $\begin{array}{c}\text { Control } \\
\text { Post } \\
(\mathrm{N}=302)\end{array}$ & $\begin{array}{c}\text { Intev. } \\
\text { Post } \\
(\mathrm{N}=321)\end{array}$ \\
\hline Ever heard of STIs & 27.5 & 31.8 & 55.0 & 65.7 \\
Ever heard of HIV / AIDS & 66.9 & 69.7 & 96.0 & 98.5 \\
\hline & & & & \\
Knows any STI symptoms in women & 5.7 & 3.5 & 13.6 & 18.7 \\
Knows any STI symptoms in men & 3.4 & 3.5 & 11.7 & 19.2 \\
Persons heard of STIs & $\mathbf{8 3}$ & $\mathbf{1 0 4}$ & $\mathbf{1 6 6}$ & $\mathbf{2 1 5}$ \\
\hline & & & & \\
Knows that a person can get HIVIAIDS by sharing & 90.6 & 90.8 & 89.7 & 92.9 \\
a needle of infected persons & & & & \\
Knows that a woman with HIVIAIDS can transmit & 79.7 & 82.5 & 66.9 & 65.8 \\
the virus to her baby through breast-feeding & 24.8 & 36.8 & 55.5 & 75.2 \\
Knows that there is a test for HIVIAIDS & $\mathbf{2 0 2}$ & $\mathbf{2 2 8}$ & $\mathbf{2 9 0}$ & $\mathbf{3 2 2}$ \\
\hline Persons heard of HIVIAIDS
\end{tabular}


STI risk perception and preventive behavior: STI preventive behaviors are closely linked with self-perception of risk of contracting STIs and HIV/AIDS. Since selfreports of risky behavior were very low this hypothesis could not be tested using the survey results.

Post survey reports showed that 15 percent of women and 11 percent of men felt that, theoretically, husbands might have extramarital sexual partners during their wife's pregnancy; only two men (one in the control group and one in the intervention group) and no women reported any extramarital sexual relations in the postpartum period and only one felt he had some chance of getting STI/HIV and reported consistent condom use with the extramarital partner. With such low acknowledgement of extramarital relationships, risk perceptions were correspondingly low. Most felt that they had little or no chance of contracting an STI. Condom use to prevent STI/HIV was mentioned by 14 percent of women and 4 percent of men in the intervention group and did not differ significantly from the control group.

In order to assess STI preventive behavior among those at risk, the analysis first assessed actual risk and risk perception among men and women. STI risk was assessed based on a positive response to any of the three questions related to 1) self perception of risk; 2) spouse had other sexual partners; and 3) self or spouse had GU/UD.

Of the 10 intervention group women who were at risk of an STI, only five had ever used condoms and two were currently using condoms. Of the 15 control group women who were at risk, five had ever used and two were currently using condoms. Among men, of the 21 from the intervention group who were at risk of an STI using the above definition of risk, nine (43 percent) were currently using condoms. Sixteen of these men have ever used condoms with their wife. Similarly, of the 28 control group men at risk of an STI, 19 said they had ever used and nine were currently using condoms with their wife. Statistical tests of significance on this data were not possible due to the small numbers acknowledging risky sexual behaviors or STI symptoms. 


\section{Hypothesis 3: Exposure to the intervention will increase knowledge of clients and providers about the dual protection provided by condoms.}

Currently in India male condoms are the only method of family planning available that offers dual protection during sexual relations; counseling focused on this characteristic of condoms and knowledge of dual protection was determined for providers as well as for men and women clients in pre and post surveys.

Providers' knowledge of dual protection: Providers' knowledge about dual protection was assessed in a pretest and immediate posttest as part of the six-day MiM training, during which they were trained to provide clients with information on condoms and demonstrate their use on penis models. The question asked was: "What does dual protection mean?"

Results show that knowledge of dual protection provided by condoms increased from 75 percent to 100 percent among doctors and from 50 percent to 100 percent among ANMs (for more information on the providers assessment, refer to MiM Research Update 1, March 2001). Knowledge, and presumably use of that knowledge in client providerinteractions, increased as a result of the intervention

Clients' knowledge of dual protection: Clients' knowledge was assessed through the following three questions from different sections of the questionnaire:

1. Is there a family planning method that protects against STIs and HIV/AIDS?

2. What are condoms used for?

3. Why did you use condoms?

Among men and women who have heard of STIs or HIV/AIDS, significantly more men from the intervention group reported that condoms protect from STIs and HIV/AIDS than among the controls but there was no significant difference in women's knowledge (Table 11). When men and women were asked what condoms are used for, a significantly higher proportion of men and women from the intervention group reported that condoms are used for dual protection. Although the women from the intervention group differed significantly on dual protection knowledge in the post survey, the net 
difference from pre to post survey was small and not statistically significant (see Table 7). Interestingly, however, when the question "What did you use condoms for?" was asked to those who reported having ever used condoms, more women (13 percent) than men (4 percent) reported to have used condoms for dual protection. The analysis suggests that both men and women primarily see condoms as a family planning method, although women currently using the condom value its protection against STIs more than men.

Table 11: Knowledge of Dual Protection from Condoms - POST Survey

\begin{tabular}{|c|c|c|c|c|}
\hline & \multicolumn{2}{|c|}{ Women (\%) } & \multicolumn{2}{|c|}{ Men (\%) } \\
\hline & Control & Interv. & Control & Interv. \\
\hline \multicolumn{5}{|l|}{$\begin{array}{l}\text { Is there any FP method that protects } \\
\text { against STIs and HIV }\end{array}$} \\
\hline Yes, condoms & 59.9 & 67.8 & 80.3 & $91.3^{*}$ \\
\hline No or Don't know & 40.1 & 32.2 & 19.8 & 8.7 \\
\hline \multirow[t]{2}{*}{ Men/women heard of STIs/HIVIAIDS } & 202 & 230 & 295 & 323 \\
\hline & \multicolumn{2}{|c|}{ N.S. } & \multicolumn{2}{|c|}{$z=3.32, p<0.05$} \\
\hline \multirow[t]{2}{*}{$\begin{array}{l}\text { Know that condoms offer dual protection } \\
\text { All men and women }\end{array}$} & $\begin{array}{l}38.4 \\
302\end{array}$ & $\begin{array}{l}48.0^{*} \\
327\end{array}$ & $\begin{array}{l}79.5 \\
302\end{array}$ & $\begin{array}{l}88.6^{* *} \\
327\end{array}$ \\
\hline & \multicolumn{2}{|c|}{$Z=2.13, p<0.05$} & \multicolumn{2}{|c|}{$z=2.62, p<0.05$} \\
\hline Why she/he used condoms? & & & & \\
\hline To protect from pregnancy & 87.4 & 85.7 & 97.9 & 96.5 \\
\hline To protect from STIs and HIVIAIDS & 0.0 & 1.1 & 0.5 & 0.0 \\
\hline $\begin{array}{l}\text { To protect from both pregnancy and } \\
\text { STIs/HIV }\end{array}$ & 12.6 & 13.2 & 1.6 & 3.5 \\
\hline Men and women reported condom use & 135 & 174 & 184 & 226 \\
\hline
\end{tabular}

Hypothesis 4: Exposure to the intervention will have a positive effect on female syphilis testing and appropriate management and treatment of urethral discharge in men and genital ulcers in men and women.

This hypothesis was measured using service statistics and responses self-reported by men and women in the post survey:

1. Number of pregnant women tested for syphilis in intervention and control clinics;

2. Number of women who had a positive RPR test who were counseled and treated. Number of husbands also treated, counseled and BCC materials provided; and

3. Prevalence of urethral discharge and genital ulcers obtained from clinic records and self-reported by clients.

Antenatal screening for syphilis: As recommended by WHO, the intervention attempted to have all pregnant women tested once during their pregnancy for syphilis using the RPR test. Service statistics show that ninety-two percent of antenatal women were tested for syphilis in the intervention clinics over the two years of implementation of 
the intervention (Table 12). Among control clinics only one clinic offered RPR tests to clients on site but the standard protocol, though not explicitly mandating a test for all pregnant woman, gave providers the option of referring the client to the hospital for a test. Service statistics show that 16 percent of women from the control clinics were tested.

The number of women testing RPR positive was very low. In the entire two-year period four women and three of their husbands tested positive for syphilis using the RPR test. In three cases the couple received complete treatment while in one case treatment was incomplete and the couple could not be followed up because there was inadequate contact information to locate them.

Table 12: Syphilis Testing and RPR Results: Year 2001 and 2002

\begin{tabular}{|l|c|c|}
\hline \multirow{2}{*}{ RPR tests and results } & \multicolumn{2}{c|}{ Total } \\
\cline { 2 - 3 } & Control & Intervention \\
\hline Number of clients registered for ANC & 3534 & 2836 \\
\hline Number of tests conducted & 568 & 2613 \\
\hline Percent of new ANC clients tested for syphilis & 16 & 92 \\
\hline Number tested positive & 0 & 4 \\
\hline Number treated & 0 & 4 \\
\hline Number partners treated & 0 & 3 \\
\hline \hline
\end{tabular}

The post survey asked women if they had been tested for syphilis. The results show that only 13 percent of the women knew that their blood had been tested specifically for syphilis. As this proportion is much lower than that of service statistics, it suggests that women were not properly informed of what blood tests had been carried out.

\section{Syndromic management of genital ulcer and urethral discharge among men:}

The intervention was designed to ask men attending the male counseling if they had any symptoms of genital ulcers or urethral discharge. Two years of the intervention service statistics show that only one man presented with what was diagnosed as genital herpes, and two with complaints of urethral discharge. All of them were treated and their wives also received treatment. There were no genital ulcer self-reports among women documented in service statistics. 
In the POST survey, five women reported having had a GU and 35 men had a GU or UD, in the last six months. Of the 35 men, about one-third had sought any treatment, and one-half of these sought treatment from ESIC. These numbers are larger than those reported in service statistics. Even though these numbers are modest, this discrepancy seems to suggest that men and women are reluctant to admit current symptoms during counseling, but more comfortable mentioning having had symptoms over the past six months during interviews. Treatment seeking behavior among the respondents suggests that women reporting a symptom were more likely to seek treatment than men, and that almost half of the cases sought treatment outside the ESIC health care system. Although the intervention greatly improved syphilis testing among pregnant women, the very small number of RPR positive cases, and cases reporting UD or GU does not allow us to make any conclusions about appropriate care-seeking by men and women faced with symptoms of an STI.

\section{Hypothesis 5: Exposure to the intervention will have a positive effect on inter- spousal communication and partner support on reproductive health matters.}

This hypothesis was operationally divided into two parts, and results were assessed using data from the post survey:

5A: Increased inter-spousal communication

1. Did individuals talk to their spouses about STIs and HIV, baby's health, breastfeeding, using a condom, using a family planning method.

2. Equitable decision-making on sexual relations, family planning use, method choice, baby's health.

5B: Increased male involvement

1. During maternity care for the last pregnancy, was the husband involved during any of the following times: accompanied to the clinic, in the room during consultations or counseling, in the room during examination, nearby during labor and delivery, in the room during FP consultations, accompanied during PP visit and child immunization?

2. Did husband encourage wife to breastfeed the baby?

Couple communication: Analysis of inter-spousal communication among couples in the pre survey showed that control women reported higher spousal discussions on family planning use, STIs and HIV/AIDS, breastfeeding and new baby's health than 
intervention women. In the post survey the reference period had changed to "since your child was born". Significantly more intervention than control women reported discussions on key postpartum topics (Table 13). There was increased spousal communication on family planning use, baby's health and breastfeeding but not on STIs and HIV/AIDS. There was a significant difference in reported discussions on STIs/HIV/AIDS and family planning use between intervention and control men.

Table 13: Spousal Communication on Reproductive Health Issues-POST Survey

\begin{tabular}{|c|c|c|c|c|c|c|}
\hline \multirow{2}{*}{$\begin{array}{l}\text { Discussions with } \\
\text { spouse since baby's } \\
\text { birth/preg. Ended }\end{array}$} & \multicolumn{2}{|c|}{ Women (\%) } & \multirow{2}{*}{$\begin{array}{c}\text { Z- } \\
\text { statistic }\end{array}$} & \multicolumn{2}{|c|}{ Men (\%) } & \multirow{2}{*}{$\begin{array}{c}\text { Z- } \\
\text { statistic }\end{array}$} \\
\hline & $\begin{array}{l}\text { Control } \\
(\mathrm{N}=302)\end{array}$ & $\begin{array}{c}\text { Intev. } \\
(\mathrm{N}=327)\end{array}$ & & $\begin{array}{l}\text { Control } \\
(\mathrm{N}=302)\end{array}$ & $\begin{array}{c}\text { Intev. } \\
(\mathrm{N}=327)\end{array}$ & \\
\hline Discussions about & & & & & & \\
\hline STIs, HIVIAIDS & 9.9 & 13.5 & N.S & 25.8 & 47.7 & $4.91^{*}$ \\
\hline Family planning use & 63.9 & 84.1 & $4.94^{*}$ & 69.8 & 88.7 & $5.00^{*}$ \\
\hline Baby's health & 88.4 & 94.5 & $2.29^{*}$ & 93.7 & 94.8 & N.S. \\
\hline Breastfeeding & 74.8 & 89.0 & $3.91^{*}$ & 91.7 & 94.5 & N.S \\
\hline
\end{tabular}

On questions related to who decides about key reproductive health issues, the statistical tests based on the net difference from pre to post survey (Table 14) show that intervention group women reported significantly higher joint decision-making on family planning, sexual relations and issues pertaining to care seeking for themselves and a sick child. The control and the intervention groups were similar at pre survey.

Table 14: Proportion Reporting Joint Decision-Making

\begin{tabular}{|c|c|c|c|c|c|c|c|}
\hline \multirow[t]{2}{*}{ Joint Couple Decisions } & \multicolumn{3}{|c|}{$\begin{array}{l}\text { Women } \\
\text { PRE (\%) }\end{array}$} & \multicolumn{3}{|c|}{$\begin{array}{l}\text { Women } \\
\text { POST (\%) }\end{array}$} & \multirow{2}{*}{$\begin{array}{l}\text { z-statistics } \\
\text { based on } \\
\text { PRE-POST } \\
\text { differences }\end{array}$} \\
\hline & $\begin{array}{c}\text { Cont. } \\
(\mathrm{N}=302)\end{array}$ & $\begin{array}{c}\text { Intev. } \\
(\mathrm{N}=327)\end{array}$ & $\begin{array}{c}z- \\
\text { statistic }\end{array}$ & $\begin{array}{c}\text { Cont. } \\
(\mathrm{N}=302)\end{array}$ & $\begin{array}{c}\text { Intev. } \\
(\mathrm{N}=327)\end{array}$ & $\begin{array}{c}\mathbf{z -} \\
\text { statistic }\end{array}$ & \\
\hline $\begin{array}{l}\text { When to have another } \\
\text { child }\end{array}$ & 70.7 & 78.5 & N.S. & 84.8 & 90.5 & N.S. & N.S. \\
\hline $\begin{array}{l}\text { Whether women can go } \\
\text { to clinic if unwell }\end{array}$ & 51.3 & 47.9 & N.S. & 66.9 & 73.1 & N.S. & $2.53^{*}$ \\
\hline $\begin{array}{l}\text { Whether to use family } \\
\text { planning }\end{array}$ & 62.0 & 61.0 & N.S. & 76.8 & 90.5 & $3.93^{*}$ & $3.79^{*}$ \\
\hline $\begin{array}{l}\text { What family planning } \\
\text { method to use }\end{array}$ & 59.7 & 59.2 & N.S. & 78.8 & 90.2 & $3.33^{*}$ & $2.92^{*}$ \\
\hline $\begin{array}{l}\text { Whether to take a sick } \\
\text { child to clinic }\end{array}$ & 70.5 & 63.2 & N.S. & 81.1 & 90.2 & $2.55^{*}$ & $4.54^{*}$ \\
\hline $\begin{array}{l}\text { Whether to have sexual } \\
\text { relations }\end{array}$ & n.a. & n.a. & $\begin{array}{c}\text { Not } \\
\text { asked }\end{array}$ & 83.4 & 92.4 & $2.63^{*}$ & \\
\hline
\end{tabular}


Male involvement and support in maternity care: In ESIC clinics, husbands typically accompany wives to their early ANC visits. However, they usually wait in the waiting room or outside and generally are not invited to join their wives during consultations. The intervention had a significant positive effect on the proportion of women who reported their husbands' presence during consultation or counseling, who were "nearby" during labor and delivery and who were with them during family planning consultations and postpartum visits. ${ }^{1}$ Significantly more men $(87$ percent verses 76 percent) and women (55 percent verses 35 percent) from the intervention group reported that husband was involved during any of the following maternity events: antenatal counselling, examination, labor and delivery or FP consultations, compared to the control group. However, though one of the MiM efforts was directed at making ANC clinics male-friendly, fewer than 50 percent of intervention husbands participated at these times. As culturally expected, almost no husbands were present during their wives' ANC examination in either control or intervention groups.

On the other hand, two-thirds of husbands of both groups accompanied wives for the index child immunization. Husbands' encouragement for breastfeeding was uniformly high, suggesting that cultural norms encouraging breastfeeding are still strong.

\footnotetext{
${ }^{1}$ Slightly different wording of the question for males and females may have produced the discrepancy in reports of husband being nearby during labor and delivery. Women were asked whether their husband was "near", while husbands were asked if they were "nearby". Women may have interpreted this to imply close proximity, while men may have responded affirmatively if they were in the hospital complex.
} 
Table 15: Husband's Involvement in Maternity Care as Reported by Women and Men - POST Survey

\begin{tabular}{|c|c|c|c|c|c|c|}
\hline \multirow{2}{*}{$\begin{array}{c}\text { Husband's Involvement in } \\
\text { Maternity Care }\end{array}$} & \multicolumn{2}{|c|}{ Women \% } & \multirow{2}{*}{$\begin{array}{c}\mathrm{z-} \\
\text { statistic }\end{array}$} & \multicolumn{2}{|c|}{ Men \% } & \multirow{2}{*}{$\begin{array}{c}\mathrm{z-} \\
\text { statistic }\end{array}$} \\
\hline & $\begin{array}{c}\text { Cont. } \\
(\mathrm{N}=302)\end{array}$ & $\begin{array}{l}\text { Intev. } \\
(\mathrm{N}=327)\end{array}$ & & $\begin{array}{l}\text { Cont. } \\
(\mathrm{N}=302)\end{array}$ & $\begin{array}{l}\text { Intev. } \\
(\mathrm{N}=327)\end{array}$ & \\
\hline \multirow{5}{*}{$\begin{array}{l}\text { During your maternity care was } \\
\text { your husband involved in: } \\
\text { Accompanied during ANC } \\
\text { visit and wait } \\
\text { Present in room during } \\
\text { consultations/ counseling } \\
\text { In the room during } \\
\text { examinations } \\
\text { Nearby during labor and } \\
\text { delivery } \\
\text { In the room during FP } \\
\text { consultations }\end{array}$} & 86.4 & 90.5 & N.S. & 94.7 & 92.7 & N.S. \\
\hline & 15.6 & 32.4 & $4.21^{*}$ & 33.8 & 24.8 & $2.08^{*}$ \\
\hline & 0.7 & 2.1 & N.S. & 3.6 & 3.7 & N.S. \\
\hline & 21.2 & 30.7 & $2.29^{*}$ & 66.1 & 80.4 & $3.42^{*}$ \\
\hline & 12.3 & 27.8 & $4.17^{*}$ & 22.5 & 33.6 & $2.62^{*}$ \\
\hline \multirow{4}{*}{$\begin{array}{l}\text { Women and men whose index } \\
\text { child survived for more than } 7 \\
\text { days } \\
\text { Accompanied during PP } \\
\text { visit } \\
\text { For child immunization } \\
\text { Husband encouraged wife } \\
\text { to breastfeed the baby }\end{array}$} & 282 & 312 & & 282 & 312 & \\
\hline & 47.2 & 57.7 & $2.1^{*}$ & 59.2 & 43.9 & $3.16^{*}$ \\
\hline & 66.3 & 67.6 & N.S. & 72.0 & 64.7 & N.S. \\
\hline & 95.4 & 89.1 & N.S. & 93.3 & 94.6 & N.S. \\
\hline
\end{tabular}

${ }^{*} p<0.05$, N.S. Not Significant

\section{Hypothesis 6: Exposure to the intervention will have a positive effect on selected indicators of infant health (immunizations and breastfeeding practices).}

The questions in the survey that operationalized the hypothesis were:

1. Did the infant receive any immunization?

2. Who took the baby for immunization?

3. How old was the baby when you started other foods or liquids?

Immunization: There was no significant difference in levels of immunization between the two groups (Table 16). Levels of immunization were uniformly high in both intervention and control groups reflecting the general awareness about the need for immunization present in Delhi's population. The recently conducted NFHS 2 reports 95 percent of children aged 12-23 months received any immunization (IIPS and Macro, 2002). 
Table 16: Immunization of the Index Child- POST Survey

\begin{tabular}{|l|c|c|}
\hline \multirow{2}{*}{ IMMUNIZATION } & \multicolumn{2}{|c|}{ Women POST (\%) } \\
\cline { 2 - 3 } & $\begin{array}{c}\text { Control } \\
(\mathrm{N}=282)\end{array}$ & $\begin{array}{c}\text { Intervention } \\
(\mathrm{N}=312)\end{array}$ \\
\hline Baby received immunization & 96.5 & 97.4 \\
\hline $\begin{array}{l}\text { Person took the baby for } \\
\text { immunization }\end{array}$ & & \\
Wife & 47.4 & 39.0 \\
Husband & 0.4 & 1.3 \\
Both & 48.9 & 57.4 \\
Other & 3.4 & 2.3 \\
\hline Number of times baby received & & \\
immunization & & 2.3 \\
$\quad$ Once & 2.9 & 17.4 \\
$\quad$ Twice & 6.3 & 30.2 \\
Three times & 54.0 & 50.2 \\
Four or more times & 36.7 & $\mathbf{3 . 6}$ \\
$\quad$ Mean no. of times & $\mathbf{3 . 4}$ & $\mathbf{3 0 5}$ \\
\hline Number of babies received & $\mathbf{2 7 2}$ & \\
immunization & & \\
\hline
\end{tabular}

However, there is concern that the full course of immunization may not be complete. In the POST survey 91 percent of infants from the control group and 80 percent of infants from the intervention group had three or more immunization visits.

Breastfeeding practices: Table 17 shows that the intervention did not have a positive impact on all breastfeeding practices. There were significant differences in breastfeeding practices between the two groups, but some were in the wrong direction: more control women continued exclusive breastfeeding until six months than intervention women. While it is not clear why this occurred, it seems as if the intervention inadvertently encouraged earlier supplementation. This was despite the reported clientprovider communication that took place during ANC on breastfeeding practices and breastfeeding as a contraceptive (Table 3). 
Table 17: Breastfeeding Practices Among Mothers- POST Survey

\begin{tabular}{|c|c|c|}
\hline \multirow[b]{2}{*}{ Particulars } & \multicolumn{2}{|c|}{ Women POST (\%) } \\
\hline & $\begin{array}{l}\text { Control } \\
(\mathrm{N}=282)\end{array}$ & $\begin{array}{l}\text { Intervention } \\
(\mathrm{N}=312)\end{array}$ \\
\hline Ever breastfed & 99.6 & 100.0 \\
\hline $\begin{array}{l}\text { How soon after birth baby received breast milk } \\
\text { Within the first hour }\end{array}$ & 47.3 & $\begin{array}{c}63.1^{* *} \\
(7=328)\end{array}$ \\
\hline Within one day & 31.0 & 19.2 \\
\hline Later than one day & 19.6 & 16.6 \\
\hline Don't remember & 0.4 & 1.0 \\
\hline No response & 1.4 & 0.0 \\
\hline $\begin{array}{l}\text { Currently feeding anything else besides breast milk } \\
\text { Index child surviving }\end{array}$ & $\begin{array}{l}51.4 \\
\mathbf{n}=\mathbf{2 7 6}\end{array}$ & $\begin{array}{l}75.5^{*} \\
z=5.20 \\
n=306\end{array}$ \\
\hline Exclusive Breastfeeding & & \\
\hline Not feeding anything else at the time of PP interview & 48.6 & 24.5 \\
\hline $\begin{array}{l}\text { Did not feed anything besides breastmilk until } 6 \\
\text { Months }\end{array}$ & 62.0 & $\begin{array}{c}49.3^{*} \\
z=-2.60\end{array}$ \\
\hline $\begin{array}{l}\text { Did not feed anything besides breastmilk until } 3 \\
\text { Months }\end{array}$ & 83.3 & 76.6 \\
\hline Not breastfeeding at time of interview & 8.3 & 8.5 \\
\hline $\begin{array}{l}\text { Mean age of child when started other foods } \\
\text { (Among those who started feeding other things besides } \\
\text { breast-milk) }\end{array}$ & $\begin{array}{l}3.7 \text { months } \\
142\end{array}$ & $\begin{array}{l}3.8 \text { months } \\
231\end{array}$ \\
\hline
\end{tabular}

Encouraging data however are seen in the larger proportion of intervention women who mentioned breastfeeding within the first hour and first day, although about one-fifth of women in both groups still followed the old practice of not beginning breastfeeding on the first day. A significantly higher proportion of the intervention group women reported that they breastfed their baby within the first hour, although this is still not near 100 percent. Also, conforming to recommended practices that infants should receive supplementary food in addition to breast milk starting at six months of age, although intervention women initiated supplementation prematurely, at the time of post interview between six and nine months after the expected date of delivery, significantly more of them were supplementing their babies' diet compared to control women: 25 percent of the infants of women in the intervention group as compared to 49 percent in the control group were still exclusively breastfed. The median age at which supplements were added was three-and-a half months. 
Obstetric danger signs: A secondary hypothesis was added to the study in 2000. The secondary hypothesis stated that: More women in the intervention group than in the control group will have correct knowledge of obstetric danger signs and seek care in a timely fashion if faced with any one of these.

This hypothesis was added to the outcome measures when the researchers realized that this benefit of the intervention was being measured but the proposal had neglected to mention a specific hypothesis. This was done well before the end of the study and before data collection was completed.

In the pre survey 15 percent of intervention group women and 20 percent of control group women reported knowing any danger signs to look out for during pregnancy. Comparison of the knowledge of danger signs among women in the POST survey shows that the proportion that knew any danger signs, although still low, was significantly higher in the intervention group women (24 percent) than the control group women (13 percent) $(\mathrm{z}=3.02, \mathrm{p}<0.05)$. The most commonly known symptoms were fever, swelling of face and hands, and high blood pressure. There was no appreciable difference in knowledge of danger signs among men and only eight percent of the men knew any symptoms. 
Table 18: Actual Experiences of Danger Signs and Care Seeking Practices-POST Survey

\begin{tabular}{|c|c|c|c|c|}
\hline \multirow[b]{2}{*}{ Danger Signs and Care seeking Practices } & \multicolumn{2}{|c|}{ Women } & \multicolumn{2}{|c|}{ Men } \\
\hline & $\begin{array}{l}\text { Control } \\
(\mathrm{N}=302)\end{array}$ & $\begin{array}{c}\text { Intev. } \\
(\mathrm{N}=327)\end{array}$ & $\begin{array}{l}\text { Control } \\
(\mathrm{N}=302)\end{array}$ & $\begin{array}{c}\text { Intev. } \\
(\mathrm{N}=327)\end{array}$ \\
\hline \multicolumn{5}{|l|}{$\begin{array}{l}\text { Had complications in pregnancy or soon } \\
\text { after delivery }\end{array}$} \\
\hline Fever & 21.5 & 10.4 & 15.2 & 9.8 \\
\hline Abnormal bleeding & 7.3 & 3.4 & 8.3 & 4.0 \\
\hline Swelling of face and hands & 11.9 & 5.2 & 14.2 & 8.5 \\
\hline High BP & 9.6 & 7.9 & 6.3 & 7.9 \\
\hline Long labor & 5.3 & 2.1 & 4.0 & 3.4 \\
\hline Rupture of membranes before due date & 7.9 & 5.5 & 1.3 & 0.9 \\
\hline Foul smelling discharge & 0.7 & 0.6 & 0.0 & 0.0 \\
\hline Had any complications & $\begin{array}{r}37.7 \\
(114)\end{array}$ & $\begin{array}{c}\mathbf{2 3 . 2}^{*} \\
(\mathbf{7 6}) \\
(z=-3.34)\end{array}$ & $\begin{array}{l}34.7 \\
(105)\end{array}$ & $\begin{array}{c}\mathbf{2 3 . 2}^{*} \\
(\mathbf{7 6}) \\
(z=-2.68)\end{array}$ \\
\hline Had only ONE complication & 19.2 & $\begin{array}{c}15.9 \\
(N . S .)\end{array}$ & 23.2 & $\begin{array}{c}15.5^{*} \\
(z=-2.05)\end{array}$ \\
\hline Had TWO complications & 12.2 & $\begin{array}{c}4.3^{*} \\
(z=-3.02) \\
\end{array}$ & 8.9 & $\begin{array}{c}4.9 \\
\text { (N.S.) }\end{array}$ \\
\hline Had THREE or MORE complications & 6.3 & $\begin{array}{c}3.0 \\
(N . S .)\end{array}$ & 2.6 & $\begin{array}{c}2.7 \\
(N . S .)\end{array}$ \\
\hline \multicolumn{5}{|l|}{$\begin{array}{l}\text { Care seeking during presence of danger } \\
\text { sign }\end{array}$} \\
\hline Go to dispensary & 30.7 & 44.7 & 57.1 & 44.7 \\
\hline Go to hospital & 36.0 & 30.3 & 27.3 & 39.5 \\
\hline Went to private practitioner & 14.9 & 17.1 & 0.0 & 3.9 \\
\hline Home remedy & 3.5 & 1.3 & 4.8 & 2.6 \\
\hline Other & 1.8 & 0.0 & 0.0 & 3.9 \\
\hline Nothing & 13.2 & 6.6 & 10.5 & 5.3 \\
\hline Number of cases & (114) & (76) & (105) & (76) \\
\hline
\end{tabular}

In the post survey, men and women were asked if there had been any danger signs during the last maternity. The danger signs mentioned in the post survey were: fever, swelling of hands and face, abnormal bleeding and prolonged labor. Significantly fewer men and women from the intervention group than the control group reported to have had danger signs during the last maternity (Table 18). Intervention group women with a danger sign were instructed during ANC to go directly to the hospital rather than the dispensary, but no significant differences between the groups were observed.

Hypothesis 7: Exposure to the intervention will have a positive effect on both the clients' and providers' satisfaction with antenatal and postpartum care services provided at the dispensaries. 
This hypothesis was tested using the post survey for clients and focus group interviews and observations for providers.

Client Satisfaction: Clients' satisfaction was examined by asking them the following questions:

PRE survey

1. Do you/your husband feel welcome in the antenatal clinic?

2. How can husbands help you during maternity care?

POST survey

1. Do you feel that counseling was helpful?

2. Did counseling cause any problem within the family?

3. Did you feel comfortable during counseling?

4. Were providers comfortable during counseling?

5. Would you to go back to the dispensary if you needed to discuss sexual or reproductive health?

6. Would you recommend that husbands be involved in their wives' maternity care?

All measures of client satisfaction were uniformly high and did not vary much between intervention and control groups. In the intervention group pre survey more men than women thought that husbands were welcome at the ANC clinics. Of the 12 percent of men who said they did not feel welcome, the main reasons given were: not enough time with doctors; long waiting time for registration; and the behavior of staff. Women valued their husbands' help in queuing for them at the registration desk and negotiating clinic procedures, besides looking after their other children, and helping with household chores.

The same question was not asked in the POST survey, but all the men and women who reported receiving counseling said that they felt comfortable during counseling. Almost all the clients from both control (94 percent) and intervention (98 percent) groups said they would visit the dispensary again for similar services. Significantly more women in the intervention group were of the view that ESIC should invite husbands to participate in wives' maternity care $(\mathrm{z}=2.37, \mathrm{p}<0.05)$ and would recommend husbands' involvement in maternity care to friends and others family members $(\mathrm{z}=2.48, \mathrm{p}<0.05)$. Most men felt 
they should be involved in maternity care (97 percent of control and 100 percent of intervention group).

Other questions related to satisfaction show that clients also expressed greater satisfaction with family planning methods (See Table 9) and in discussions with providers (See Table 4). Women were also asked whether they and providers felt comfortable during couple counseling sessions and if counseling caused any problems to them. Among those who mentioned receiving counseling all the women ( 88 of intervention group and 5 of control group) said that they and providers were comfortable during discussions, and none reported that couple counseling caused any problems within their family.

Provider satisfaction: Provider satisfaction was measured through qualitative methods, using in depth interview with managers and focus group discussions with male and female doctors and ANMs involved in providing antenatal and postnatal interventions.

The following topics were used to assess providers' satisfaction:

1. Provider likes and dislikes about the new service practices

2. Perceived increased work load due to additional activities in the new service structure

4. Satisfaction with the new services

5. Providers' perceptions of clients' satisfaction with new services

The focus group discussions with male and female doctors and ANMs, and indepth interviews with the doctors in charge of the three intervention dispensaries show that they considered the new Men in Maternity intervention useful and felt that it should be continued. The main reasons given were the increase in clients' satisfaction with services and their own satisfaction. The fundamental change mentioned was the way they now approach clients and communicate with them. Greater efficiency made up for time required for counseling. The providers mentioned that husbands were keen to participate in the new services. Most groups of providers were able to talk and counsel couples about sensitive topics including condom use. 
The following are some quotes from the three focus group discussions:

"In my 15 years of service to ESIC, this is the first time I have come across such a good program. I am happy to be a part of it."

"If there is the interest, the time and space for counseling could be created."

"Earlier we were like tape recorders now the counseling is more personalized."

\section{Hypothesis 8: The intervention will produce the desired results in a cost-effective manner both in terms of its marginal cost increases as well as any additional opportunity costs that are incurred for the new services.}

A detailed cost effectiveness analysis is beyond the scope of this report, however a cost assessment was carried out and its outcome was reported to ESIC. ESIC administrators thought that the intervention was feasible and affordable for their agency and fit their intentions of male involvement in reproductive health services.

Cost analysis methodology: The cost analysis documented the resources used to plan and introduce the intervention as well as the additional resources required to keep the intervention running. Results included resources that were provided by the Population Council as well as those from ESIC. For ESIC, resources were distinguished as resources that were paid for (such as additional supplies for the clinics), and those that were donated or represented an opportunity cost to the organization (such as the provider time used to attend training or meetings that was therefore not available for seeing clients). The key resources of interest were: labor, materials, and equipment. As the study was being launched, a series of monitoring forms was developed to document time spent on the intervention by program personnel as well as support staff from the Population Council, any expenses related to materials for training, or supplies given to the clinics. Calculations are in Indian rupees, the exchange rate at the time of the study was approximately Rs. $47.0=\$ 1$.

One question of critical interest to ESIC was whether providers (doctors and/or ANMs) would have sufficient time to provide the integrated services in addition to their 
current responsibilities. As a comparison, the three control clinics which were similarly sized and geographically similar were also studied. The purpose of examining the comparison clinics was to help estimate the additional resources required by the intervention clinics to deliver the integrated maternity care, family planning, and STI services, specifically, the change in provider time use as well as the financial outlays required to implement and conduct the integrated service delivery. Therefore an estimate of the number of hours per year spent by each type of provider to provide the integrated services was calculated. This calculation was based upon the total additional time spent by providers to deliver integrated services over and above the time spent by providers to deliver antenatal services in the comparison clinics. Because male doctors play a role in the delivery of integrated services (male counseling, STI syndromic management for men, and some couple counseling) their additional service delivery hours were reported separately from female doctors.

Key findings: The results of the analysis focus on two different time periods: the preparation and training period, July to December 2000, and; two years of program implementation, January 2001 to December 2002. This distinction was made so that the start-up costs of implementation could be separated from the recurrent cost associated with maintaining the intervention. For each period, the additional time required by ESIC personnel (doctors, ANMs and laboratory technicians) to participate in the intervention was reported followed by a report on the value of the resources used for the intervention, the amount of those resources which were direct expenditures by ESIC, and the amount of the total resources which comprised opportunity costs to ESIC (that is, no additional financial expenditures were incurred by ESIC in the provision of these resources, but these were resources which ESIC had expended by redeployment of staff and some expenditure from their funds for drugs and supplies).

During the preparation and training period (July to December 2000), the emphasis was on preparation of the training materials and other materials to support the clinicians in the intervention clinics. This planning was led by the Population Council staff in Delhi and supplemented by local consultants. A total of Rs. 929,773 was spent of which the 
Council provided Rs. 735,277 and ESIC covered Rs. 109 as direct costs and Rs. 194,387 as opportunity costs for staff and materials used. The out-of-pocket costs to ESIC were negligible. The opportunity cost of sending staff to the initial training accounted for 200 doctor hours per clinic and 200 ANM hours per clinic, but only 6 hours per clinic of lab technician time. With 4 doctors and 4 ANMs trained per clinic, this came to 50 hours per clinician or just over one week spent in training.

The three intervention clinics began provision of the integrated services in January 2001 and assessments continued until December 2002. In order to estimate the resources used for service delivery, differences between intervention and control clinics in the number and types of client-provider encounters as well as the length of client-provider encounters were monitored. The monitoring system to capture service statistics from the clinics was undertaken with a small direct observation study of interactions to estimate contact times. In addition to the service delivery, periodic review meetings and refresher trainings were held for the intervention clinics to reinforce the training messages and to discuss any problems with the intervention. Project staff from the Population Council facilitated these activities. Table 19 estimates the time spent by ESIC staff on these activities. Table 20 describes the resources used to support these activities. For the service delivery time the measure used was the additional time spent by providers over and above the time that was being spent in the comparison clinics.

Table 19: Net Increase in Provider Time for Program Implementation for Three Clinics (January 2001 - December 2002)

\begin{tabular}{|l|c|c|c|}
\hline \hline Provider Type & $\begin{array}{c}\text { Total Additional } \\
\text { Time } \\
\text { (Hrs.) }\end{array}$ & $\begin{array}{c}\text { Review / Refresher } \\
\text { Meetings } \\
\text { (Hrs.) }\end{array}$ & Service Delivery \\
(Hrs.)
\end{tabular}

Keeping in mind that the time reported in Table 19 was for three clinics and for a two-year period, the additional clinician time required per clinic was approximately 160 hours per year for all doctors and ANMs at a given clinic. Since there were four clinicians of each type per clinic, the additional time per clinical provider was 40 hours per year or about one week of service (or less than one hour per week). This time was 
allocated at approximately one-third for review and refresher meetings and two-thirds for service delivery. The lab technician time was less, about 38 hours per year, which was similar to the per provider time requirement of one week per year. Unlike the clinicians, this time was almost exclusively used for service delivery. The average additional doctor time for service delivery per clinic was 64 hours per year (range $50-237$ hours) for female doctors and 46 hours per year (range $19-79$ hours) for male doctors. For ANMs, the average additional time for service delivery per clinic was 101 hours per year (range $53-169$ hours). For laboratory technicians, the average additional time for service delivery per clinic was 38 hours per year (range $25-58$ hours). In addition to the time spent on service delivery, there was, on average, 50 hours per year per clinic of doctor's time spent on periodic review and refresher meetings (range 36-81 hours). The ANMs spent an average of 57 hours per year per clinic on refresher and review meetings (range $24-92$ hours). No additional staff was hired.

Table 20: Total Resources Used for Program Implementation for Three Clinics (January 2001 - December 2002)

\begin{tabular}{|c|c|c|c|c|}
\hline \hline Resource & Total Value & $\begin{array}{c}\text { Resources } \\
\text { Provided by } \\
\text { Population } \\
\text { Council } \\
\text { (Rs.) }\end{array}$ & $\begin{array}{c}\text { Paid for as } \\
\text { "new costs" } \\
\text { by ESIC }\end{array}$ & $\begin{array}{c}\text { Opportunity Cost } \\
\text { to ESIC }\end{array}$ \\
\hline Labor & (Rs.) & (Rs.) & (Rs.) \\
\hline Materials & 573,833 & 276,272 & 0 & 297,561 \\
\hline Total & 265,741 & 248,236 & 14,705 & 2,800 \\
\hline \hline
\end{tabular}

(US \$ 1= Rs. 47 approx. at the time of the study)

There were relatively few additional expenditures by ESIC to support the intervention; these include the additional supplies used to diagnose and treat STIs and the condoms given during the counseling sessions. However, almost Rs. 300,000 were incurred as an opportunity cost for provider time for the three intervention clinics. As described above, the majority of this time was spent on the provision of the integrated services. No new equipment was required. 


\section{DISCUSSION}

The MiM study was implemented in a setting that was already providing services to men and where health insurance coverage was provided to all, so that there were no fees paid by clients. In such an environment two sets of conclusions were drawn from the study about the feasibility and acceptability of such an intervention and the impact of the intervention measured in terms of the eight study hypotheses.

\section{Was the intervention feasible and acceptable in a setting where previously men had not been included in maternity services?}

The ease of introducing the male participation component into antenatal care suggests that the intervention was indeed feasible and acceptable. Service statistics and observations by the researchers showed that men's participation in their wives' antenatal care began as soon as providers informed women that their husbands were welcome to participate in the consultation. Responses on questions about the desire for male involvement in maternity care showed that both men and women felt men should and could be involved. The responses on the post survey suggested that the actual amount of male involvement in maternity care was also fairly high and the program was enthusiastically accepted by both providers and clients. A review of client responses for each component of the intervention showed that the antenatal couple counseling and universal syphilis testing were most successfully implemented, while the newly implemented mother-baby postnatal clinic and individual or same-sex group counseling on STI prevention and treatment components were less successfully implemented since there was no significant increase in related knowledge and behaviors using the study's indicators. It is, however, important to mention that the doctors (especially male) felt that their improved counseling skills and ability to treat STIs was appreciated by couples and that they were counseling and treating more STIs in their general clinics.

The feasibility of the intervention was assessed in terms of the additional burden in personnel and time requirements as well as the additional supplies and equipment needed to integrate the intervention into the antenatal and postpartum clinics. No new

personnel were recruited for providing these services and the cost analysis showed that 
the increase in provider time and the additional cost for the intervention were well accepted by ESIC.

Did the intervention positively influence women and men's reproductive health, particularly through appropriate postpartum family planning use and STI and HIV/AIDS primary and secondary prevention?

To summarize the impact of the intervention, hypotheses were tested, based on statistical analysis of key variables in the pre and post intervention surveys, service statistics, and from interviews and discussions with providers. The results show that the intervention had a mixed effect in terms of acceptance of the eight study hypotheses. Generally, the family planning interventions were more successful than the STI preventive interventions and there was little evidence of any effect on infant health measures.

Ho 1 Family planning: The intervention showed significant increase in key indicators of family planning knowledge. Current use of family planning at six to nine months postpartum and intention to use a method among non-users was significantly higher among the intervention group than the control group.

$\mathbf{H}_{\mathbf{0}} 2$ STIs: The intervention did not have any significant effect on the very low level of STI knowledge or realistic self-risk perception. However there was an increase in awareness and use of condoms for dual protection as reported by women and men. With the very low acknowledgement of STI risk-taking, the hypothesis that the intervention would lead to improved protective behavior could not be tested.

Ho 3 Dual Protection: There was a significant change in men and women's knowledge of dual protection. Providers' (particularly ANMs') knowledge of dual protection increased after the MiM training and providers were observed routinely mentioning that condoms provide dual protection while demonstrating condom use on a penis model. 


\section{$\mathrm{H}_{0} 4$ Appropriate management and treatment of syphilis, genital ulcers and}

male urethral discharge: The intervention led to a significant increase in pregnant women being tested for syphilis at the intervention clinics. While 92 percent of women in intervention clinics had a RPR test only 16 percent of clients from control dispensaries had been tested for syphilis. Four pregnant women were tested positive for syphilis; of these, three couples received complete treatment. Only one man and no women reported any genital ulcer and only a few men reported and were treated for urethral discharge. In all reported cases, both the individual and their spouse were counseled and treated, suggesting that this approach does encourage better partner treatment. Although the numbers were too small to conduct statistical tests, the fact that on-site treatment and counseling were available suggests that this approach is feasible.

$\mathbf{H}_{\mathbf{0}} 5$ Spousal communication: The intervention had a significant impact on spousal communication and decision-making. A significantly larger proportion of women reported talking to their husbands about family planning and child care. The increase in STI related discussions was not statistically significant. There was a significant increase in joint couple decision-making on reproductive health issues. Male involvement was significantly higher in the intervention group suggesting that the male participation had a positive impact on wife's support during pregnancy.

$\mathrm{H}_{0} 6$ Infant health: There were mixed results on child health indicators. Levels of immunization were high in both groups. Breastfeeding was initiated earlier, however, exclusive breastfeeding at six months was lower in the intervention group than the control group. Breastfeeding practices were stressed during ANC and were one of the main components for the postpartum counseling. Findings of low attendance to this newly instituted service suggest that the postnatal component of the intervention may not have been understood or accepted as readily as the antenatal components; clients were not used to a postnatal mother and baby check-up at the dispensary and may have confused this with the routine visit to the hospital where the birth took place. In addition, the country's Universal Immunization Campaign encourages immunization at clinics close to the child's home and this could have led to some women not wanting a repeat visit at the 
dispensary. Better understanding of the purpose of this visit and coordination between dispensaries and the hospital will improve this.

Secondary $\mathbf{H}_{\mathbf{0}}$ Danger signs: The need to assess and educate couples on danger signs during pregnancy and to make a plan about where to go if a complication occurred was part of the intervention from its inception and was an important component of the BCC materials and job aids developed. During the early phase of the study the researchers involved agreed that it was important to measure the effect of the intervention on this key life-saving information provided to couples and a secondary hypothesis was added. Results show that knowledge of danger signs did increase among the intervention group women, but remained well below desired levels among both men and women.

$\mathbf{H}_{\mathbf{0}} 7$ Satisfaction: A majority of men and women from both groups reported that men should participate in maternity. Measures of client and provider satisfaction were consistent in suggesting that the intervention components increased client and provider satisfaction with antenatal and postnatal services. A significantly larger proportion from the intervention group said they would recommend it to family and friends. Providers also mentioned instances of increased client satisfaction and reported their own enthusiasm about the new services in focus group discussions. The clinic managers felt the intervention fitted in well with ESIC routine and should be continued.

$\mathbf{H}_{\mathbf{0}} 8$ Cost: Analysis of the cost of implementing the intervention found that the total marginal expenditure per year per dispensary on supplies and materials was approximately Rs. 44,290 or less than $\$ 1000$, an amount considered affordable by ESIC. Also, since no new staff was used for the intervention and changes in staff routines were possible without increasing providers' work hours, ESIC found the intervention to be institutionable as designed and a value added to existing services and decided to expand the intervention to seven other Delhi clinics. 


\section{Limitations of the Study}

The results of statistical analysis should be interpreted with some caution as there were several important limitations to the results due to study design and implementation constraints that are mentioned below:

Study design: The study used a quasi-experimental design that acknowledges that the two groups may not be completely comparable. Also, it was decided not to recruit men in the control group for a PRE measure to avoid influence of the interview and its inadvertent "testing" effect. Differences in the control and intervention group of women were found. The non-simultaneous collection of data first at control sites and then at intervention sites may have introduced some period or seasonal effects. Since all the sites were ESIC dispensaries and there was communication between providers, there may have been some small degree of contamination between the intervention and control clinics by providers who knew about the intervention.

Selection criteria: The selection criteria of 10-26 weeks gestation at enrolment in the survey excluded a sizable number of women who receive antenatal care at ESIC dispensaries as many come for antenatal care for the first time in their third trimester. The surveyed group was thus skewed towards women who attend ANC earlier in pregnancy and was not fully representative of ESIC clientele. However, both control and intervention groups were subjected to the same selection criteria and their comparison continues to be valid.

Loss to follow-up: There was a large and greater than forecasted loss to follow up that may have biased the results of the post survey since there were significant differences in background characteristics of those lost to follow-up and those contacted at follow-up. Men and women who were younger, less educated and less likely to have FP and STI, HIV/AIDS knowledge were disproportionately reduced in both intervention and control followed up in the post survey. But, with some exceptions, comparing groups who were not lost to follow-up, the intervention did improve some important outcomes. 
Setting for interviews: The two differing venues of the interview may have influenced the responses given by clients since the pre was conducted in health facilities and the post was conducted at home. Many families live in single room houses and so have little privacy. The pressure of the husband's needing to get back to work may have hastened answers during interviews at clinics. Since these biases were present for both intervention and controls the comparisons continue to be valid.

\section{UTILIZATION OF RESULTS}

The success of the MiM intervention in increasing men's participation in maternity care and in raising client and provider satisfaction with maternity services assessed by ESIC providers and management led to early plans for scaling up. Preliminary results from the POST survey were shared and when it became clear that the intervention had a positive impact on couple communication and family planning use and intention, these plans were finalized and the scale-up process began even before complete study results were available. Providers from the three intervention sites who had demonstrated good practice in the MiM intervention were trained to conduct a modified and condensed three-day training for other ESIC staff in order to scale up the intervention from three to 10 dispensaries in Delhi.

The successful integration of men into antenatal care has raised awareness among program planners in the Ministry of Health and Family Welfare and some NGOs of the feasibility of involving men in maternity care. Adding the intervention to the current National Reproductive and Child Health $(\mathrm{RCH})$ program is being explored.

The final results of the study have been presented at three national level meetings and two meetings within the research and program services network within Delhi. The last dissemination meeting was held in New Delhi in October 2003 where policy makers, senior officials from the ESIC and Ministry of Health and Family Welfare, USAID, Population Council, reproductive health researchers from academic institutions, and nonprofit agency and UN organization representatives were present. Discussions centered on 
how men felt about participating in their wives' care and the feasibility of the intervention in settings such as Maternal and Child Health clinics where men usually are not present.

The MiM study results have been disseminated at international meetings during the course of the study. These include presentations at the annual meetings of the Global Health Council in Washington, D.C., Population Association of America, and American Public Health Association, and the White Ribbon Alliance's International Safe Motherhood conference in Delhi. A brown-bag luncheon meeting was held at USAID/Washington in May 2003 where utilization of results and scale-up were discussed.

Another forum where the project process and results were shared was the Interagency Gender Working Group's (IGWG) meeting on Reaching Men to Improve Reproductive and Sexual Health for All held in Washington DC in September 2003.

\section{CONCLUSIONS AND RECOMMENDATIONS}

The Men in Maternity (MiM) study investigated the feasibility and impact of a new model of integrated maternity care on outcomes related to the reproductive health of men, women, and current pregnancy in ESIC clinics in Delhi. Its results can be extrapolated to similar large public health care facilities in urban areas in India. The specific objectives of increasing postpartum family planning use and promoting STI preventive practices in men and women were investigated.

Attendance of men with their wives at antenatal and postpartum clinics increased dramatically as soon as the intervention encouraged husband's participation and syphilis screening of the majority of pregnant women became a routine activity. Providers spent between five and 10 minutes per group in same-sex groups and also with individual couples, counseling them about the key messages of MiM. They were able to add this to

their existing work routine without an appreciable increase in clinic time made possible through training and use of appropriate job aids and BCC materials. 
There were some interventions that were not so easily introduced and accepted within the existing services. One of these was the six-week postnatal checkup of mother and baby and couple counseling within the existing immunization clinics. Despite encouragement during pregnancy, few couples came for the six-week postnatal clinic. Another was related to the STI management component. Very low reported rates of STI positivity (i.e.syphilis, self-reports of genital ulcers and urethral discharge among men) made implementation of STI syndromic management rare.

The majority of men and women surveyed in both groups thought male involvement in maternity care should be encouraged. Actual involvement at many stages of maternity was greater in the intervention group compared to the control group. This change in action could be directly attributed to their participation in the intervention. Another factor which was directly related to involvement was the increase in couple communication and shared decisions. The study observed that communication on issues such as family planning, breastfeeding, child care, and to a limited extent, even STIs/HIV/AIDS, were significantly higher in the intervention compared to the control group. There was also significantly more joint decision making on family planning issues in the intervention group.

One of the specific objectives of this study was to increase the use of family planning methods, appropriate to breastfeeding and STI risk status. The intervention emphasized providing complete information about the contraceptive choices available, easy postpartum access to desired methods, and reinforcing STI awareness and preventive behaviors. Knowledge about using condoms for dual protection and LAM were assessed and only knowledge of dual protection showed a significant increase in the intervention group women. Knowledge and practice of LAM remained very low. The post survey recorded an increase in family planning use by 13 percentage points for women and 17 percentage points for men compared to the control group. Condoms accounted for a large proportion of this increase. The intention to use a method among non-users of family planning also showed an increase with both men and women from the intervention group. 
The other specific objective of this study was to raise knowledge among couples about STIs and HIV/AIDS and primary and secondary preventive behavior. Data analysis showed no significant increase in STI knowledge and prevention. Although post survey knowledge of symptoms of STIs and HIV/AIDS increased, these levels are still unacceptably low and few acknowledged any STI risk. Despite advocating STIs/HIV/AIDS prevention through counseling messages and BCC material, the differences between groups on STI preventive behaviors were small. The study did however report increases in condom use.

One of the ways to understand whether the intervention was the reason behind these changes is to measure the intervention process and the levels of satisfaction of clients with the new MiM services. The key components of the intervention such as couple counseling and individual counseling for men and women were mentioned by a significantly larger proportion of intervention group clients than control group clients. The POST survey reported increased client-provider interaction and increased satisfaction by clients with antenatal and postpartum services and with the family planning method they used. Providers expressed their high level of satisfaction with the new services during focus group discussions and in-depth interviews.

The large ESIC health care structure and the characteristics of men and women using their services suggests that these interventions can be implemented in large public sector facilities used by couples in India's urban centres. The high levels of acceptance of the importance of male involvement and men and women's almost universal interest in husband's involvement in antenatal and postnatal care suggest that with few exceptions the intervention can contribute to improvements in reproductive health and greater couple communication in other service delivery settings in India.

Knowledge of the cost of implementing such an intervention becomes vital in the decision whether to institutionalize and expand such services after the experimental phase is over. The study recorded an additional annual opportunity cost of approximately Rs. 50,000 (US $\$ 1,063$ ) per dispensary, for providing the integrated maternity care services as 
reflected in the additional time use of providers. Actual cost of additional materials and supplies Rs. 44, 290 (US \$942) was considered easily affordable by the implementing organization.

With some changes in design to improve the impact of breastfeeding practices and STI knowledge and attitudes about risky behavior, the authors recommend that the total intervention package can be implemented and will have an impact on men and women's reproductive health, future unwanted fertility and consequently on pregnancy outcomes. 


\section{BIBLIOGRAPHY}

Caleb Varkey, Leila. March 2001 “Involving Men in their Wives' Antenatal and Postpartum Care in India." Research Update. Frontiers in Reproductive Health Program, Population Council, New Delhi.

Caleb Varkey, Leila, et al. May 2002. "Men in Maternity Study: Establishing the Intervention". Internal Process Report, Frontiers in Reproductive Health Program, New Delhi.

Das, Anjana, et al. April 2002. "Men in Maternity Study." Research Update. Frontiers in Reproductive Health Program, Population Council, New Delhi.

Frontiers in Reproductive Health Program, New Delhi. 2001. Modules for InService Training: Employees' State Insurance Corporation Health Care Providers.

International Institute for Population Sciences (IIPS) and ORC Macro. 1995. National Family Health Survey (NFHS-1), India.

International Institute for Population Sciences (IIPS) and ORC Macro. 2002. National Family Health Survey (NFHS-2), India.

Campbell, Michael J. and David Machin. 1999. "Medical Statistics - A Commonsense Approach.” Third Edition. John Wiley \& Sons Ltd. England.

Mishra, Anurag, et al. July 2002. "Men in Maternity Study: Results from the PRE -Intervention Survey of Pregnant Women and their Husbands at Three Intervention and of Only Women at Three Control ESIC Dispensaries in Delhi, India”. Preliminary Findings, Frontiers in Reproductive Health Program, Population Council, New Delhi.

Mishra, Anurag, et al. July 2002. "Men in Maternity Study: A Summary of the Findings from the PRE -Intervention Interviews with Women and their Husbands Attending Antenatal Clinics of ESIC Facilities in Delhi." Research Update. Frontiers in Reproductive Health Program, Population Council, New Delhi.

Murthy, Nirmala, Lakshmi Ramchander, Pertti Pelto and Akhila Vasan, 2002. Dismantling India's contraceptive target system. In Nicole Haberland and Diana Measham (eds.). Responding to Cairo: Case studies of changing practice in reproductive health and family planning. Population Council, New York.

National AIDS Control Organisation. 2001. "NACO Sentinel Survellance Reports." India.

Raju, Saraswati and Ann Leonard. 2000. "Men as Supportive Partners in Reproductive Health- Moving from Rhetoric to Reality”. Population Council, New Delhi. 


\section{Appendix 1}

Annual service statistics among participating dispensaries 2000-2002

\begin{tabular}{|l|c|c|c|c|c|c|c|}
\hline & \multicolumn{3}{|c|}{ Year 2001 } & \multicolumn{3}{c|}{ Year 2002 } & TOTAL \\
\cline { 2 - 7 } & Disp. 1 & Disp. 2 & Disp. 3 & Disp. 1 & Disp. 2 & Disp. 3 & \\
\hline $\begin{array}{l}\text { New ANC cases } \\
\text { registered }\end{array}$ & 416 & 573 & 493 & 410 & 485 & 459 & 2836 \\
\hline Couple Counseling & 264 & 337 & 322 & 288 & 355 & 331 & 1897 \\
\hline Female Counseling & 268 & 565 & 506 & 288 & 973 & 487 & 3087 \\
\hline Male Counseling & 182 & 224 & 315 & 155 & 247 & 314 & 1437 \\
\hline $\begin{array}{l}\text { RPR tests } \\
\text { Done }\end{array}$ & 333 & 567 & 494 & 326 & 445 & 448 & 2613 \\
\hline $\begin{array}{l}\text { Postnatal } \\
\text { Counseling }\end{array}$ & 47 & 32 & 51 & 65 & 147 & 54 & 396 \\
\hline $\begin{array}{l}\text { RPR positive cases } \\
\text { recorded and } \\
\text { managed }\end{array}$ & 1 & 1 & - & & & & \\
\hline $\begin{array}{l}\text { GU/UD cases } \\
\text { recorded and } \\
\text { managed }\end{array}$ & 1 & - & - & - & - & - & 1 \\
\hline
\end{tabular}




\section{Appendix 2}

MODEL 1 Calculation of ICC and Design Effect for Outcome Indicators Based on PRE-sample of 629 Women

\begin{tabular}{|c|c|c|c|c|c|c|}
\hline $\begin{array}{l}\text { KEY OUTCOME } \\
\text { VARIABLES }\end{array}$ & $\begin{array}{c}\text { Between } \\
\text { Variance }\end{array}$ & \begin{tabular}{|c|} 
Within \\
Variance
\end{tabular} & $\begin{array}{c}\mathrm{N}= \\
\text { Pre sample }\end{array}$ & $\begin{array}{c}\text { Total } \\
\text { variance }= \\
\text { (Bet var.- } \\
\text { within } \\
\text { Var.)/n } \\
\end{array}$ & $\begin{array}{c}\text { ICC = tot. } \\
\text { var./(tot. var } \\
+ \text { Within } \\
\text { Var.) }\end{array}$ & $\begin{array}{l}\text { Diff at Post }= \\
1+\operatorname{ICC} *(N-1)\end{array}$ \\
\hline Discussed FP & 0.423 & 0.247 & 105 & 0.0017 & 0.0067 & 1.7 \\
\hline Know any danger signs & 0.354 & 0.13 & 105 & 0.0021 & 0.0161 & 2.7 \\
\hline knowledge of STIs & 0.333 & 0.221 & 105 & 0.0011 & 0.0048 & 1.5 \\
\hline Knowledge of HIV/AIDS & 0.41 & 0.242 & 105 & 0.0016 & 0.0066 & 1.7 \\
\hline Knowledge of Dual protection & 2.481 & 5.089 & 105 & -0.0248 & -0.0049 & 0.5 \\
\hline $\begin{array}{l}\text { Ever used condoms with } \\
\text { husband }\end{array}$ & 0.184 & 0.208 & 105 & -0.0002 & -0.0011 & 0.9 \\
\hline FP intention after birth & 0.331 & 0.23 & 105 & 0.0010 & 0.0042 & 1.4 \\
\hline Women ever used FP method & 0.206 & 0.203 & 105 & 0.0000 & 0.0001 & 1.0 \\
\hline & & & \multicolumn{3}{|c|}{ Design Effect } & 1.42 \\
\hline
\end{tabular}


MODEL 2 Calculation of ICC and Design Effect for Outcome Variables Based on PRE Sample of 1,067 Women

\begin{tabular}{|c|c|c|c|c|c|c|c|c|}
\hline $\begin{array}{l}\text { KEY OUTCOME } \\
\text { VARIABLES }\end{array}$ & $\begin{array}{c}\text { Between } \\
\text { Variance }\end{array}$ & $\begin{array}{c}\text { Within } \\
\text { Variance }\end{array}$ & $\begin{array}{c}\mathbf{N}= \\
\text { Pre } \\
\text { sample }\end{array}$ & $\begin{array}{c}\text { Total } \\
\text { variance } \\
=\quad(\text { Bet } \\
\text { var.- } \\
\text { within } \\
\text { Var. }) / \mathbf{n} \\
\end{array}$ & $\begin{array}{c}\text { ICC = tot. } \\
\text { var./(tot. } \\
\text { var+within } \\
\text { Var.) }\end{array}$ & $\begin{array}{l}\text { diff at } P R E= \\
1+I C C^{*}(N-1)\end{array}$ & $\begin{array}{c}\text { diff at post } \\
\text { using PRE } \\
\text { ICC }= \\
1+I C C^{*}(n-1)\end{array}$ & $\begin{array}{l}n=\text { Post } \\
\text { sample }\end{array}$ \\
\hline Discussed FP & 1.087 & 0.247 & 178 & 0.0047 & 0.0187 & 4.3 & 3.0 & 105 \\
\hline Know any danger signs & 0.76 & 0.124 & 178 & 0.0036 & 0.0280 & 6.0 & 3.9 & 105 \\
\hline knowledge of STIs & 0.554 & 0.208 & 178 & 0.0019 & 0.0093 & 2.6 & 2.0 & 105 \\
\hline $\begin{array}{l}\text { Knowledge of } \\
\text { HIV/AIDS }\end{array}$ & 0.967 & 0.246 & 178 & 0.0041 & 0.0162 & 3.9 & 2.7 & 105 \\
\hline $\begin{array}{l}\text { Knowledge of Dual } \\
\text { protection }\end{array}$ & 7.244 & 5.794 & 178 & 0.0081 & 0.0014 & 1.2 & 1.1 & 105 \\
\hline $\begin{array}{l}\text { Ever used condoms } \\
\text { with husband }\end{array}$ & 0.543 & 0.293 & 178 & 0.0014 & 0.0048 & 1.8 & 1.5 & 105 \\
\hline FP intention after birth & 0.486 & 0.233 & 178 & 0.0014 & 0.0061 & 2.1 & 1.6 & 105 \\
\hline $\begin{array}{l}\text { Women ever used FP } \\
\text { method }\end{array}$ & 0.202 & 0.195 & 178 & 0.0000 & 0.0002 & 1.0 & 1.0 & 105 \\
\hline & & \multicolumn{4}{|c|}{ DESIGN EFFECT } & 2.87 & 2.10 & \\
\hline
\end{tabular}

